\title{
Poly-gamma-glutamic acid biopolymer: a sleeping giant with diverse applications and unique opportunities for commercialization
}

\author{
Pranav Nair ${ }^{1,2} \cdot$ Govinda R. Navale ${ }^{1,2} \cdot$ Mahesh S. Dharne ${ }^{1,2}$ D \\ Received: 19 January 2021 / Revised: 19 March 2021 / Accepted: 23 March 2021 / Published online: 1 April 2021 \\ (C) The Author(s), under exclusive licence to Springer-Verlag GmbH Germany, part of Springer Nature 2021
}

\begin{abstract}
Poly-gamma-glutamic acid ( $\gamma$-PGA) is a biodegradable, non-toxic, ecofriendly, and non-immunogenic biopolymer. Its phenomenal properties have gained immense attention in the field of regenerative medicine, the food industry, wastewater treatment, and even in 3D printing bio-ink. The $\gamma$-PGA has the potential to replace synthetic non-degradable counterparts, but the main obstacle is the high production cost and lower productivity. Extensive research has been carried out to reduce the production cost by using different waste; however, it is unable to match the commercialization needs. This review focuses on the biosynthetic mechanism of $\gamma$-PGA, its production using the synthetic medium as well as different wastes by L-glutamic acid-dependent and independent microbial strains. Furthermore, various metabolic engineering strategies and the recovery processes for $\gamma$-PGA and their possible applications are discussed. Finally, highlights on the challenges and unique approaches to reduce the production cost and to increase the productivity for commercialization of $\gamma$-PGA are also summarized.
\end{abstract}

Keywords Poly-gamma-glutamic acid, $\cdot$ Waste valorization, $\cdot$ Multi-nutritious, $\cdot$ Commercialization

\section{Introduction}

Microbial biopolymers are gaining worldwide attention due to their degradable, non-toxic, and eco-friendly nature compared to synthetic non-degradable materials. The market demand for biopolymer is higher due to its phenomenal properties; however, the high production cost and low yielding microbial strains is the major hurdle in the commercialization of biopolymer [1]. The main difference between biodegradable polymer (polycaprolactone) and bio-based polymer (polylactic acid) is that the former one undergoes degradation in the presence of microorganisms or other aerobic and anaerobic processes, whereas the latter one may be biodegradable (poly-lactic acid) or non-biodegradable (bio-polyethylene). Earlier biopolymers were derived from corn and other feedstocks, which raised a debate between food vs fuel, shifting the focus towards the use of lignocellulosic wastes such as rice

Mahesh S. Dharne

ms.dharne@ncl.res.in

1 Academy of Scientific and Innovative Research (AcSIR), Ghaziabad, India

2 National Collection of Industrial Microorganisms (NCIM), CSIR-National Chemical Laboratory, Pune 411008, India straw and wheat bran [2]. With advancements in research and technologies, biopolymers are finding their way from being used as food thickeners and bioplastics into high-end regenerative medicines. Out of all the biopolymers known to date, poly gamma glutamic acid ( $\gamma$-PGA) is one of the most expensive biopolymers with few milligrams at the cost of several dollars. Poly glutamic acid (PGA) is a poly(amino acid) in which glutamic acid monomers are coupled to each other via amide bonds between alpha or gamma carboxylic groups. The $\alpha$-PGA are chemically synthesized by nucleophilic polymerization of L-glutamic acid in the presence of aprotic solvents like toluene and a metal catalyst. Naturally occurring microbes are not known to synthesize $\alpha$-PGA unless genetically engineered [3]. Contrastingly, $\gamma$-PGA are synthesized by different microbes such as Natrialba aegyptiaca, Natronococcus occultus, and Fusobacterium nucleatum. Although there are different $\gamma$-PGA producer strains known, Bacillus species, especially B.licheniformis and B.subtilis are still considered as the most potent producers due to relatively higher production and productivity of $\gamma$-PGA $[4,5]$.

The biosynthesis of $\gamma$-PGA is solely based on the microenvironment and the type of organism producing it. Some may produce $\gamma$-PGA to evade antibodies and antimicrobial peptides, whereas others may use it as a source of nutrients during starvation $[4,5]$. Depending on these factors, $\gamma$-PGA can either be cell- 
bound to elicit virulence or maybe secretory to withstand an extreme environment. As $\gamma$-PGA is not synthesized in a ribosomal-dependent manner, drugs such as erythromycin cannot cease $\gamma$-PGA production [6]. The $\gamma$-PGA producers can be broadly classified into three major classes: poly- $\gamma$-L-glutamic acid producer, poly- $\gamma$-D-glutamic acid producer, and poly- $\gamma-$ DL-glutamic acid producer (Table 1). The Poly- $\gamma$-glutamic acid producer can be further sub-classified depending on the exogenous supply of L-glutamic acid as L-glutamic acid-dependent producers and L-glutamic acid-independent producers. The former one is a promising producer due to the comparatively high production of $\gamma$-PGA, but the production cost is high. The latter producer has an advantage of lower production cost; however, the $\gamma$-PGA yield is also less [3, 7]. Several research groups have explored various wastes in order to reduce the production cost of $\gamma$-PGA. The use of lignocellulosic biomass such as rice straw and corncobs can be an attractive alternative for carbon source $[23,24]$. The carbon source can be further substituted using macroalgae, goose feathers, paper waste, swine, dairy, and chicken manure [8-12]. However, the major limitation with these wastes is the requirement of pretreatment for effective utilization of sugars as well as supplementing the production media with additional nutrients such as L-glutamic acid, citric acid, peptone and trace elements, further adding to the cost. Therefore, it is of utmost importance to have in-depth knowledge about different waste, their nutrient composition as well as their availability for cost-effective synthesis of $\gamma$-PGA. This review focuses on recent updates on the biosynthesis of $\gamma$-PGA by using various Bacillus strains for the economical production of $\gamma$-PGA. It also sheds light on the recovery processes, challenges that the researchers face in terms of high production cost and low-productivity, as well as strategies to overcome them.

\section{Microbial production of $\mathrm{Y}-\mathrm{PGA}$}

\subsection{Screening of $\psi$-PGA producers}

For the microbial production of $\gamma$-PGA, screening of $\gamma$-PGA producer strain is the primary step. There are three screening strategies for $\gamma$-PGA producers: the basic approach is the UV based method to confirm $\gamma$-PGA at $216 \mathrm{~nm}$ absorbance. The second approach comprises the detection of a concentric zone around the colonies in the presence of neutral red. The final approach is the formation of fibrous precipitate in the production medium by the addition of methanol/ethanol, as depicted in Fig. 1. The final characterization of $\gamma$-PGA is done by thinlayer chromatography (TLC), Fourier transform infrared spectroscopy (FTIR), circular dichroism (CD-spectra), gel permeation chromatography (GPC), differential scanning calorimetry (DSC), thermogravimetric analysis (TGA), and nuclear magnetic resonance (NMR) analysis [13, 14].

\subsection{L-glutamic acid-dependent strains for $\mathrm{Y}$-PGA production}

\subsubsection{Bacillus subtilis}

Over the past decades, extensive efforts have been made for the production of $\gamma$-PGA from Bacillus subtilis after its discovery by Ivanovic and his co-workers in the form of a capsule in B. anthracis [15]. Wu et al. manipulated the cell membrane permeability with additives like tween 80 or DMSO, which facilitated the utilization of abundant glucose and glutamate for enhanced production of $\gamma$-PGA. With the addition of glycerol, the 2-oxoglutarate dehydrogenase activity was suppressed, which helped to direct the carbon flux for glutamate synthesis, thereby stimulating $\gamma$-PGA production from $26.7 \mathrm{~g} / \mathrm{L}$ to $31.7 \mathrm{~g} / \mathrm{L}$. Although Tween 80 showed a negative impact on cell growth, it could trigger iso-citrate dehydrogenase activity for enhanced glutamate production, thus playing a pivotal role in $\gamma$-PGA synthesis with the yield of $34.4 \mathrm{~g} / \mathrm{L}$ in B. subtilis CGMCC 0833 [16]. Lee et al. reported the ability of $\gamma$-PGA to inhibit angiotensin-converting enzyme at $1.25 \mathrm{ppm}$ in B.subtilis D7, which could aid in reducing hypertension [17]. Bajaj and Singhal demonstrated that $\gamma$-PGA produced from $B$. subtilis R 23 had a flocculating ability of 30/optical density (O.D.) at $7.5 \mathrm{ppm}$ in the presence of $\mathrm{Ca}^{2+}$. The researcher explained that the purity of $\gamma$-PGA depends upon the carbon source utilized by B. subtilis IF03335 [18]. The

Table 1 Types of poly gamma glutamic acid producers

\begin{tabular}{|c|c|c|c|c|}
\hline \multirow{2}{*}{$\begin{array}{l}\text { Poly- } \gamma-\mathrm{L}-\text { glutamic acid } \\
\text { producer }\end{array}$} & \multicolumn{2}{|c|}{ Poly- $\gamma$-DL- glutamic acid producer } & \multirow{2}{*}{$\begin{array}{l}\text { Poly- } \gamma \text {-D-glutamic acid } \\
\text { producer }\end{array}$} & \multirow[t]{2}{*}{ Ref. } \\
\hline & $\begin{array}{l}\text { L-glutamic acid-dependent } \\
\text { producers }\end{array}$ & $\begin{array}{l}\text { L-glutamic acid-independent } \\
\text { producer }\end{array}$ & & \\
\hline - B. halodurans & B. subtilisIFO 3335 & B. subtilis $5 \mathrm{E}$ & B. anthracis & $\begin{array}{l}{[6,15,47,} \\
66]\end{array}$ \\
\hline - B. megateriums & B. licheniformisATCC 9945A & B. subtilis TAM-4 & & \\
\hline - Natrialbaaegyptiaca & B. subtilisMR-141 & B. licheniformis $\mathrm{S} 173$ & & \\
\hline - Natronococcusoccultus & B. subtilissubsp. chungkookjang & B. licheniformis A35 & & \\
\hline
\end{tabular}




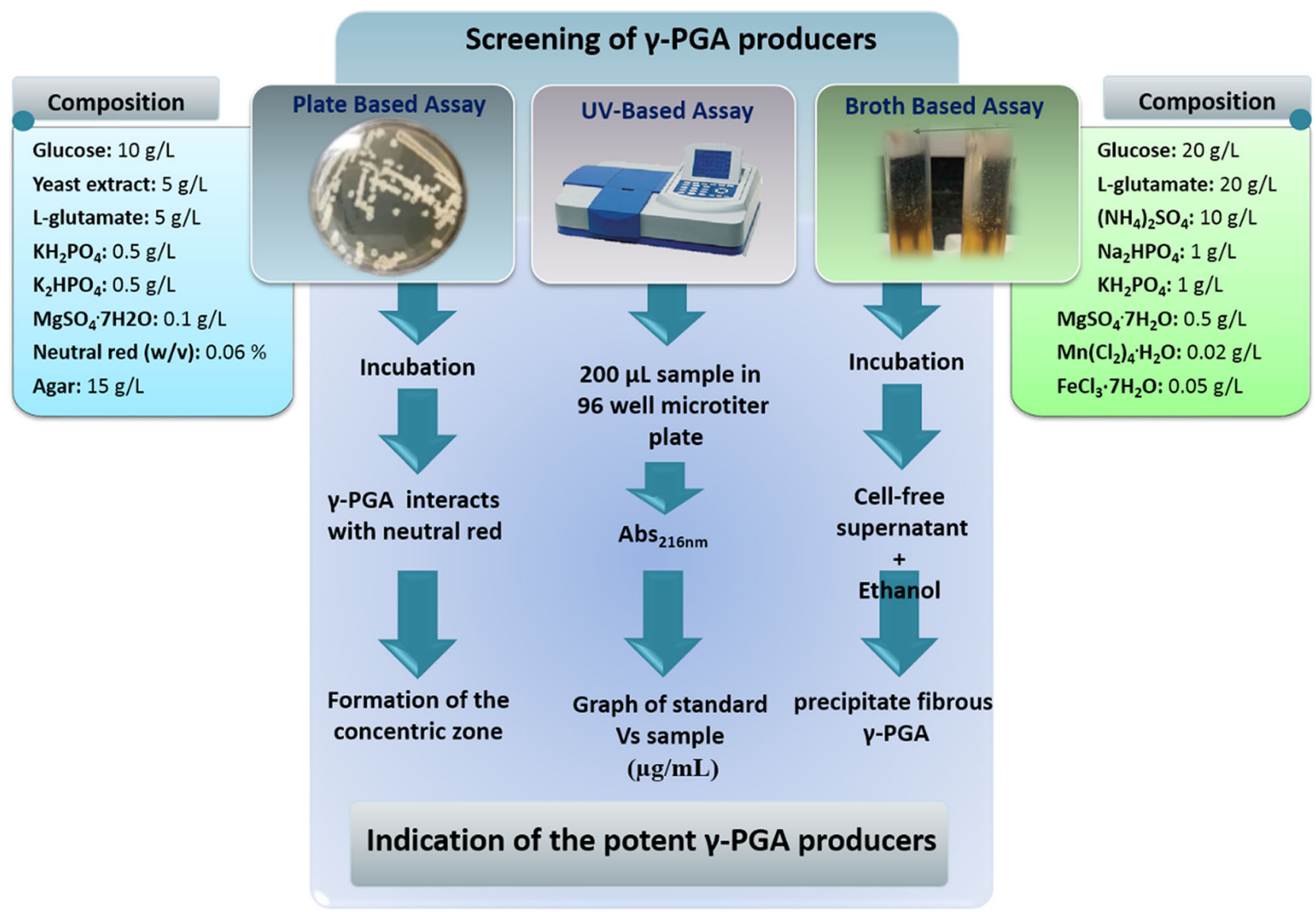

Fig. 1 Screening approach for isolating potential $\gamma$-PGA producing strain $[13,14]$

addition of glucose produced polysaccharides as the byproduct, whereas the use of citric acid resulted in the synthesis of highly pure $\gamma$-PGA [19]. Zhang et al. statistically optimized solid-state fermentation for $\gamma$-PGA production in B. subtilis ZC-5 using Plackett-Burman and Box-Behnken design. The final optimized medium yielded $65 \mathrm{~g} / \mathrm{L}$ of $\gamma$ PGA in a medium consisting of chicken manure, soybean cake, and glutamic acid extracts. This strategy has a multifarious advantage like waste valorization, lower substrate cost, decreased energy consumption, and the final fermented substrates can be used as bio-fertilizers [20]. Ju et al. demonstrated both the glutamate-dependent and independent property of B. subtilis MJ80 due to its ability to utilize L-glutamic acid and soybean from the production medium. This strain produced about $68.7 \mathrm{~g} / \mathrm{L}$ of $\gamma$-PGA with a molecular size of $1500 \mathrm{kDa}$ in a $300-\mathrm{L}$ fermenter within $72 \mathrm{~h}$ of incubation. The $\gamma$-PGA production is solely dependent on the TCA cycle, and any approach that can improve the rate transfer of oxygen would enhance the $\gamma$-PGA yield [21]. Da Silva et al. checked the effect of metabolic precursors and an oxygen-carrying agent such as polydimethylsiloxane (PDMS) on $\gamma$-PGA production. Inclusion of L-glutamine and $\alpha$-ketoglutaric acid as the metabolic precursors elevated the $\gamma$-PGA production up to
$20 \%$, and further addition of PDMS resulted in increment of oxygen mass transfer rate with the productivity of $0.97 \mathrm{~g} / \mathrm{L} / \mathrm{h}$ in B. subtilis BL53 [22].

Zhang et al. developed an eco-friendly and economical strategy to enhance the production of $\gamma$-PGA. The fishmeal wastewater can act as a cost-effective substitute for nitrogen sources, thereby decreasing its extrinsic supply into the production medium. The optimized production medium yielded $25 \mathrm{~g} / \mathrm{L}$ of $\gamma$-PGA with glucose (3\%), glutamic acid (2.5\%), and fishmeal wastewater with chemical oxygen demand of 15 [23]. Huang et al. developed a fed-batch approach by maintaining the glucose concentration at 0.3 to $1 \%$ throughout the fermentation process, which yielded 200 times the $\gamma$-PGA production as compared to normal batch cultivation. With this strategy, the production of $101 \mathrm{~g} / \mathrm{L}$ was achieved in a $10 \mathrm{~L}$ fermenter with a productivity of $2.19 \mathrm{~g} / \mathrm{L} / \mathrm{h}$ [24]. Kedia et al. investigated the impact of different media such as E, C, F, and GS medium on $\gamma$-PGA production in $B$. subtilis natto, one of the most widely used $\gamma$-PGA-producing strains. The $\mathrm{E}$ and $\mathrm{F}$ media mainly consisted of glycerol as the carbon source, whereas in GS and C media, sucrose and glucose act as carbon sources. It was observed that this strain could not utilize E medium; however, with GS medium, the yield reached around 
$28 \mathrm{~g} / \mathrm{L}$ [25]. To ensure that the glutamic acid added to the medium is being polymerized to $\gamma$-PGA, Ogawa et al. radiolabeled L-glutamic acid monomers and supplemented it to the fermentation medium, which showed radioactivity in the $\gamma$-PGA secreted by B. subtilis natto MR-141 [26]. Zhang et al. also demonstrated another greener approach for the production of $\gamma$-PGA., wherein B.subtilis NX-2 could produce around $52 \mathrm{~g} / \mathrm{L}$ of $\gamma$-PGA using cane molasses and waste liquor of monosodium glutamate, thereby reducing the cost associated with expensive media components [27]. Lignocellulosic biomass such as rice straw and wheat bran are the most widely generated agricultural biomass treated as waste in many countries. Due to a lack of knowledge about the proper disposal strategies, the biomass is burnt off, which raises many environmental concerns [28]. To address this issue, by using the same strain, Tang et al. demonstrated a twostage hydrolysis strategy for efficient retrieval of sugars from rice straw. In first stage, approximately xylose (2.2\%), glucose $(0.2 \%)$, and arabinose $(0.1 \%)$ were retrieved whereas in stage II, glucose $(2.6 \%)$ and xylose $(0.1 \%)$ were obtained. Using this approach, $\gamma$-PGA yield was $73 \mathrm{~g} / \mathrm{L}$ by continuous fermentation with the productivity of $0.8 \mathrm{~g} / \mathrm{L} / \mathrm{h}$ [29]. Similarly, corncob hydrolysate was investigated for its efficient utilization by B. subtilis HB-1, which yielded $24 \mathrm{~g} / \mathrm{L}$ of $\gamma$-PGA with the productivity of $0.6 \mathrm{~g} / \mathrm{L} / \mathrm{h}$ [30]. The metallic ions in the medium are also an important factor in the production of $\gamma$-PGA. Wu et al. reported the potential of metal ions such as $\mathrm{Mn}^{2+}$ to modulate the stereochemistry of $\gamma$-PGA secreted by $B$. subtilis $\mathrm{NX}-2$. In the absence of $\mathrm{Mn}^{2+}$ ions, the $\gamma$-PGA yield was only $9.25 \mathrm{~g} / \mathrm{L}$; however, with the addition of $\mathrm{Mn}^{2+}$ ions, the yield reached up to $28.42 \mathrm{~g} / \mathrm{L}$. With a lower concentration of $\mathrm{Mn}^{2+}$ ions in the production medium, the ratio of D-glutamate in the $\gamma$-PGA elevated from 17 to $77 \%$ due to an increase in the activity of glutamate racemase [31].

\subsubsection{Bacillus licheniformis}

This Bacillus species is a mesophilic organism known for its high $\gamma$-PGA-producing ability. Shih et al. statistically optimized four variables, namely citric acid, L-glutamic acid, $\mathrm{pH}$, and glycerol using factorial and central composite design for enhanced $\gamma$-PGA production by $B$. licheniformis CCRC 12826. With this approach, $\gamma$-PGA production increased from 5.2 to $19.8 \mathrm{~g} / \mathrm{L}$, which was about $372 \%$ higher than the traditionally used medium E [32]. By using the same strain, Yan et al. demonstrated the potential of the bio-flocculant activity of $\gamma$-PGA to replace polyacrylamide from the sugarcane industry for clarification. The presence of metal ions such as $\mathrm{Mg}^{2+}$ could enhance the flocculating ability and $\gamma$-PGA production, unlike $B$. subtilis $\mathrm{NX}-2$, which requires $\mathrm{Mn}^{2+}$ ions [33]. Bajaj et al. reported the ability of metabolic precursors to improve the molecular size and yield of $\gamma$-PGA by B. licheniformis NCIM 2324. The addition of $0.5 \mathrm{mM} \mathrm{L}-$
Glutamine and $10 \mathrm{mM} \alpha$-ketoglutarate raised the $\gamma$-PGA production to $35 \mathrm{~g} / \mathrm{l}$, indicating the enhanced activity of glutamine synthetase and aminotransferases. With this combination of metabolic precursors, the molecular size increased from 210 to $570 \mathrm{kDa}$ [34]. Du et al. investigated the effect of glycerol in B. licheniformis WBL-3 on phospholipids and ester-linked fatty acids. With glycerol in the production medium, the level of phosphatidylglycerol and cardiolipin increased, whereas that of phosphatidylethanolamine, phosphatidylserine, and phosphatidic acid decreased. Similarly, the addition of glycerol showed a substantial reduction in $\mathrm{C} 18$ fatty acid, such as oleic acid, thereby increasing the cell membrane permeability. A significant increase in $\mathrm{C} 10$ fatty acid was also observed, which might aid in enhancing the membrane fluidity implicating their function in increased $\gamma$ PGA secretion [35].

Wei et al. demonstrated a salt-induced production of $\gamma-\mathrm{PGA}$ by a halotolerant strain of $B$. licheniformis WX-02. The molecular weight and the yield of $\gamma$-PGA were reduced by increasing the salt concentration with a maximum yield of $13.86 \mathrm{~g} / \mathrm{L}$ at $8 \%$ $\mathrm{NaCl}$. Thus, the molecular weight of $\gamma$-PGA can be modulated accordingly depending on the application by increasing or decreasing the concentration of salts in the medium [36]. Cromwick et al. investigated the effect of $\mathrm{Mn}^{2+}$ on the physiology and the production of $\gamma$-PGA in B. licheniformis ATCC 9945A. The presence of $\mathrm{Mn}^{2+}$ in the range of 6.15 to $615 \mu \mathrm{M}$ can enhance the uptake of carbon sources as well as maintain high cell viability for a more extended period. However, for the production, maximum yield was achieved at $\mathrm{MnSO}_{4}$ concentration between 6.5 and $61.5 \mu \mathrm{M}$, indicating the requirement of stress condition for improved $\gamma$-PGA production. Further, the presence or the absence of $\mathrm{MnSO}_{4}$ in the fermentation medium have shown to modulate the stereochemistry of the $\gamma$-PGA (L and $\mathrm{D}$ glutamate isomeric ratio); however, the mechanism is still unknown[37]. Altun et al. reported an economically feasible strategy by using goose feathers and B. licheniformis 9945A strain. The goose feathers were hydrolyzed by keratinolytic enzymes and then added to the production medium, which yielded $5.4 \mathrm{~g} / \mathrm{L}$ of $\gamma$-PGA [8]. Similarly, waste papers were also explored as a cost-effective alternative for carbon sources yielding around $6.46 \mathrm{~g} / \mathrm{L}$ of $\gamma$-PGA by B. licheniformis WX-02 [10]. Other Lglutamic acid-dependent producers are $B$. methylotrophicus and B.amyloliquefaciens; however, they are least explored for their enhanced $\gamma$-PGA producing ability $[12,38]$.

\subsection{L-glutamic acid independent strains for -PGA production}

\subsubsection{B. subtilis}

In the previous section, we have mentioned this strain as Lglutamic acid-dependent strain, but several researchers reported this strain could produce $\gamma$-PGA without the addition of L- 
Glutamic acid. Ito et al. reported a glutamic acid independent strain B. subtilis TAM-4, which showed denovo synthesis of $\gamma$-PGA in the production medium. Out of eight carbon and nitrogen sources investigated, glucose and ammonium chloride showed a maximum yield of $13.4 \mathrm{~g} / \mathrm{L}$ within four days. The stereochemistry of $\gamma$-PGA remained constant throughout the cultivation period with the diastereomeric ratio of $\mathrm{D} / \mathrm{L}$ isomers (78:22) [39]. Zhang et al. investigated the significant factors affecting the $\gamma$-PGA biosynthesis and the endogenous supply of glutamic acid in $B$. subtilis $\mathrm{C} 10$. Assuming that the $\gamma$-PGA production in glutamic acid independent strain can be triggered by providing TCA cycle metabolites and organic acids, the effect of succinic acid, citric acid, malic acid, acetic acid, and oxalic acid on the production was assessed. The $\gamma$ PGA was not detected in the presence of acetic acid, whereas it reached a peak value of $28.3 \mathrm{~g} / \mathrm{L}$ with citric acid in the production medium. The addition of ammonium chloride further enhanced the $\gamma$-PGA production to $29 \mathrm{~g} / \mathrm{L}$. The activity of pyruvate dehydrogenase and 2-oxoglutarate dehydrogenase complex was elevated by supplementation of oxalic acid, whereas citric acid improved the isocitrate dehydrogenase and glutamate dehydrogenase activity [40]. Furthermore, the ability of a novel thermotolerant strain $B$. subtilis GXG5 to produce $\gamma$-PGA was evaluated. In the absence of L-glutamic acid, this strain could produce around $19 \mathrm{~g} / \mathrm{L}$ of $\gamma$-PGA at $50^{\circ} \mathrm{C}$, indicating its glutamate independent and thermotolerant ability [41].

\subsubsection{Bacillus licheniformis}

Soliman et al. statistically optimized different variables using Plackett-Burman design for improved $\gamma$-PGA production in B. licheniformis SAB-26. Out of the four nitrogen sources investigated, ammonium sulfate showed a maximum yield of $11.2 \mathrm{~g} / \mathrm{L}$, whereas the presence of L-glutamic acid yielded just $1.7 \mathrm{~g} / \mathrm{L}$, suggesting the L-glutamic acid independent mode of production. About fifteen independent variables were analyzed for their significance in $\gamma$-PGA production from which $\mathrm{K}_{2} \mathrm{HPO}_{4}, \mathrm{KH}_{2} \mathrm{PO}_{4},\left(\mathrm{NH}_{4}\right)_{2} \mathrm{SO}_{4}$, and casein hydrolysate showed a positive correlation for $\gamma$-PGA production by stimulating $\gamma$-PGA synthetase complex [42]. Similarly, Mabrouk et al. optimized the production with nine variables in B. licheniformis A13. The statistical analysis revealed that the yeast extracts positively impacted $\gamma$-PGA production, whereas the media volume had a negative correlation. The optimized medium composed of glucose (5\%); yeast extract $(0.2 \%) ; \mathrm{NH}_{4} \mathrm{Cl}(0.3 \%) ; \mathrm{MgSO}_{4} .7 \mathrm{H}_{2} \mathrm{O}(0.08 \%) ; \mathrm{NaCl}(0.08$ $\%) ; \mathrm{K}_{2} \mathrm{HPO}_{4}(0.64 \%)$ yielded around $28.8 \mathrm{~g} / \mathrm{L}$ of $\gamma-\mathrm{PGA}$ which was five-folds higher compared to the conventional medium [43]. In another study, Kongklom et al. demonstrated a fed-batch approach using $B$. licheniformis TISTR 1010 by feeding citric acid, glucose, and $\mathrm{NH}_{4} \mathrm{Cl}$ at a particular interval. This strategy yielded $39 \mathrm{~g} / \mathrm{L}$ of $\gamma$-PGA with a productivity of
$0.9 \mathrm{~g} / \mathrm{L} / \mathrm{h}$, which was thrice compared to formerly reported strain by the same group $[44,45]$. Other L-glutamic acid independent strains include $B$. methylotrophicus and B. amyloliquefaciens LL3 with a yield of $35 \mathrm{~g} / \mathrm{L}$ and 4.84 $\mathrm{g} / \mathrm{L}$, respectively $[5,46]$.

\section{The biosynthetic mechanism for $\mathrm{Y}-\mathrm{PGA}$ production}

As $\gamma$-PGA is quite expensive than traditional polymers it has conceptualized to replace, the only anticipated solution is to decrease the overall production cost. To address this issue, one should know the mechanism and the metabolic gene clusters impacting the $\gamma$-PGA biosynthesis, which may aid in improving the strains for enhanced production [6]. A metabolic pathway for $\gamma$-PGA production and its gene cluster has been shown in Fig. 2. The prerequisite component for $\gamma$-PGA production, L-glutamic acid, can be either exogenous or endogenous. When it is derived endogenously, the L-glutamic acid pathway is activated wherein carbon source supplemented through the medium is first converted to acetyl CoA via glycolysis followed by synthesis of $\alpha$-ketoglutaric acid via Krebs cycle. The potential precursor, $\alpha$-ketoglutaric acid, can be converted into L-glutamic acid in two distinct ways. When glutamine is absent, glutamate dehydrogenase converts $\alpha$ ketoglutaric acid and ammonium chloride to L-glutamic acid. When L-glutamine is present, 2-oxoglutarate aminotransferase catalyzes the conversion of $\alpha$-ketoglutaric acid and glutamine to L-glutamic acid. The metabolic pathway for $\gamma$-PGA biosynthesis includes the activity of enzymes such as racemase, synthase, and peptidase, etc. [6, 47, 48].

\subsection{Racemase}

The $\gamma$-PGA can either be a homopolymer such as poly- $\gamma$-Lglutamic acid, poly $-\gamma$-D- glutamic acid, or a heteropolymer like poly- $\gamma$-DL-glutamic acid. The incorporation of Lglutamic acid monomers in the growing peptide chain can either be derived from the medium or be synthesized by glutamate dehydrogenase or 2-oxoglutarate aminotransferase enzyme [49]. However, the synthesis of D-glutamic acid requires the activity of racemases, which catalysis the formation of D-glutamic acid from L-glutamic acid in the process known as racemization [5]. The $B$. subtilis consists of two glutamate racemase genes, which are homologous, namely racE, also known as $g l r$ and $y r p C$ [6]. Although $r a c E$ and $y r p C$ are not involved in $\gamma$-PGA biosynthesis, they are essential for growth in minimal (yrpC) and nutrient-rich medium ( $\mathrm{racE}$ ) [47]. Contrastingly, $g l r$ is crucial in $\gamma$-PGA synthesis by the formation of D-glutamic acid from L-glutamic acid, and its overexpression can increase the enantiomeric ratio of D-glutamate in B. licheniformis [50]. 


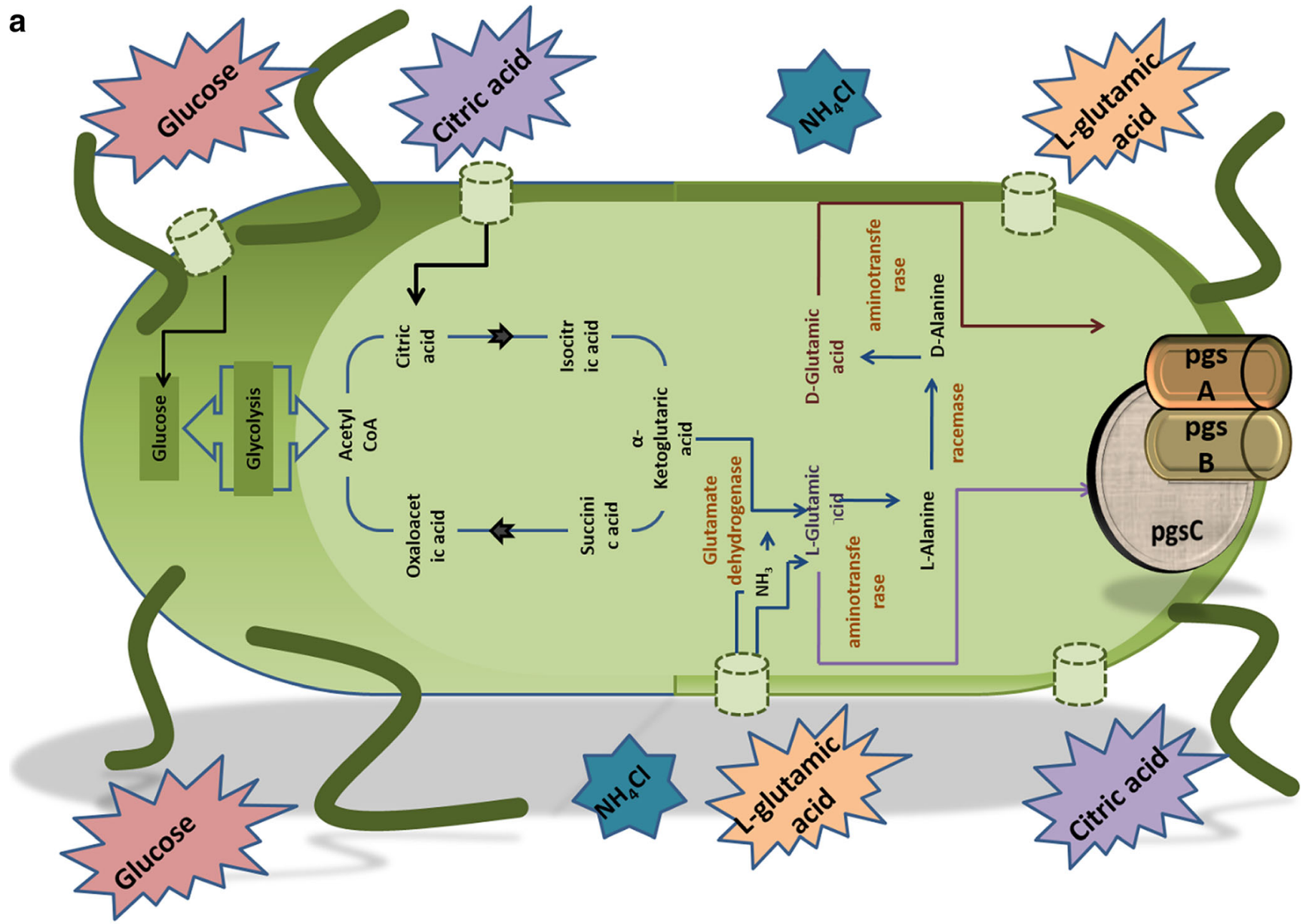

b

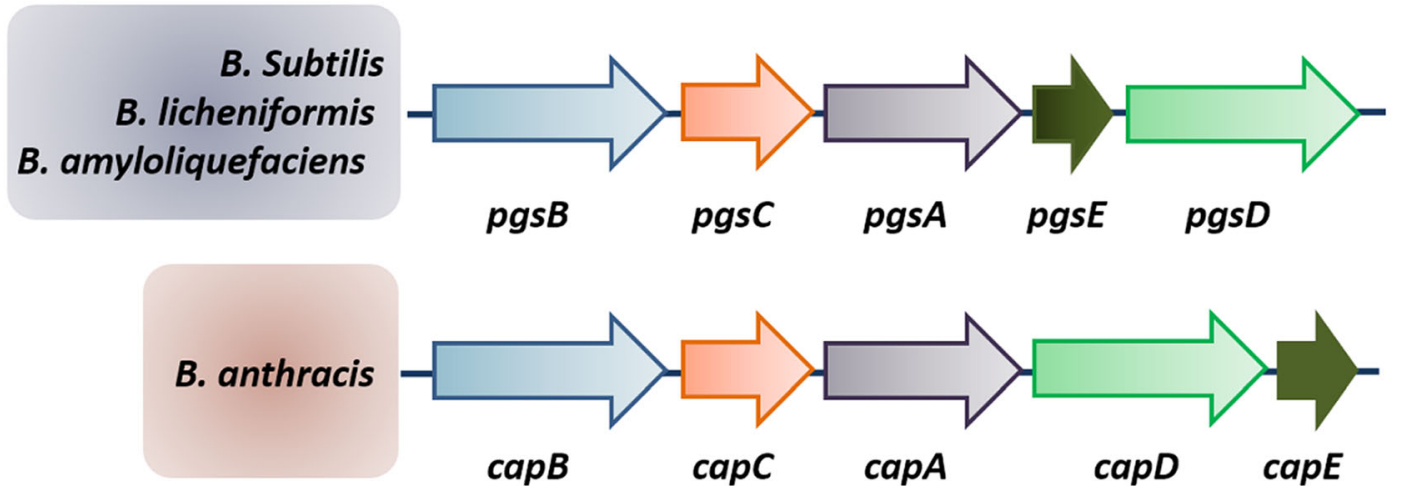

Fig. 2 A) Biosynthesis of poly gamma glutamic acid. B) The $\gamma$-PGA synthetase genes in Bacillus spp. [4, 15]

\subsection{Synthase}

In $B$. anthracis, the $\gamma$-PGA biosynthesis genes are encoded by the plasmid, whereas in some Bacillus species, these genes are inherited chromosomally [6]. The anchoring or release of synthesized $\gamma$-PGA is solely dependent on the genes involved. In the case of $B$. anthracis, the cap genes are essential for capsular formation in which $\gamma$-PGA is linked to the bacterial cell surface, whereas in B. subtilis or B. licheniformis pgs genes influence its release into the surrounding. The four sets of $c a p$ genes, namely cap $B, C, A, E$ in $B$. anthracis are homologous to pgs $B, C, A, E$ in $B$. subtilis or B. licheniformis. The entire cap gene cluster is essential for $\gamma$-PGA production; however, the significance of all the four $\mathrm{pgs}$ genes is still controversial. Some researchers have demonstrated the importance of $\mathrm{pgs}$ $B$ and $p g s C$ genes, whereas others have reported $p g s E$ gene as nonessential $[5,16]$. In the $\gamma$-PGA synthase complex, pgs $B$ and $\operatorname{pgs}_{s} C$ together constitute the catalytic unit, whereas $\operatorname{pgs}_{s} A$ 
is involved in the inclusion of L-glutamic acid monomers and further transporting the biopolymer to the cell membrane [47, $51,52]$.

\subsection{Peptidase}

During starvation or other adverse conditions, some Bacillus species secrete peptidase enzymes such as gamma-glutamyltranspeptidases (GGT) that are capable of cleaving $\gamma$-PGA with their intrinsic exo-hydrolase activity, thereby serving as a source of nutrients. To the downstream of $\operatorname{pgs} B C A$ operon is the $p g d S g e n e$, that codes for gamma-glutamyl-hydrolase, with the ability to degrade $\gamma$-PGA between the two glutamate residues. Another member of the GGT family, capD, has the dual functionality of anchorage as well as depolymerization by cleaving $\gamma$-PGA and relocating it to an acceptor molecule or water, aiding in transpeptidation or hydrolysis $[6,16]$.

\section{Bacterial fermentation and the downstream process for $\mathrm{Y}$-PGA production}

For the efficient production of microbial biopolymer $\gamma$-PGA, the media components and cultivation conditions play a crucial role as they influence the yield and the characteristic of $\gamma$ PGA. Researchers have utilized different production media containing L-glutamic acid for enhanced production of $\gamma$ PGA. However, some strains produce $\gamma$-PGA in the medium devoid of L-glutamic acid due to their intrinsic L-glutamic acid-producing ability. Apart from media, fermentation conditions are also crucial for the maximum yield of biopolymer. To date, extensive research has been carried out for the production of $\gamma$-PGA by using different fermentation media, both synthetic as well as diverse wastes, which are summarized in Tables 2 and 3, respectively.

\subsection{Metabolic engineering for the production of $Y$ - PGA}

We have discussed microbial strain and its optimized fermentation processes for improved production of $\gamma$-PGA. The production via recombinant strain is necessary for the high production of $\gamma$-PGA in the fermentation medium. Overexpression of native $\gamma$-PGA gene cluster ( $p g s B C A$ ) in Bacillus strain is the primary strategy of metabolic engineering for $\gamma$-PGA production. To date, various metabolic engineering strategies have been employed for enhancing the $\gamma$-PGA production in the native and other recombinant strains [53]. A xylose-induced

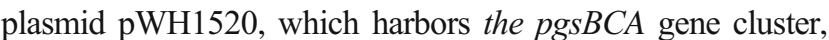
was inserted into a $\gamma$-PGA deficient strain $B$. subtilis MA41 resulting in $\gamma$-PGA production of $9 \mathrm{~g} / \mathrm{L}$ [54]. Similarly, insertion of pgs $\mathrm{BCA}$ in a strong promoter into B. subtilis DB430 resulted in $28 \mathrm{~g} / \mathrm{L} \gamma$-PGA production [55]; however, this approach is not always reproducible. The excision of hydrolase genes such as ggt (encoding gamma-glutamyltransferase) did not increase the $\gamma$-PGA yield; however, it resulted in increased molecular weight. In B. subtilis NAFM5, deleting the $c w l O$ gene resulted in the overproduction of $\gamma$-PGA compared to control with an increase in molecular weight from $240 \mathrm{kDa}$ to $490 \mathrm{kDa}$ [56]. Similar results were obtained in the case of B. amyloliquefaciens NK-c with about $28 \%$ enhanced $\gamma$ PGA production by deleting the $c w l O$ gene. Furthermore, the production was increased to $93 \%$ compared to control by excising both $c w l O$ and $p g d S$ genes [57]. In a recombinant strain of $B$. subtilis PB5522, $\gamma$-PGA production of $40 \mathrm{~g} / \mathrm{L}$ was achieved after double deleting the genes such as $p g d S$ and ggt $[58,59]$. This is so far the highest production of $\gamma$-PGA using the recombinant strains. A slight increase in $\gamma$-PGA production was observed in B. amyloliquefaciens NK-E10 after the deletion of the lux $S$ gene by making the cell more tolerant to toxic by-products [60]. In B. amyloliquefaciens LL3, wherein genes responsible for intracellular glutamate supply such as $\mathrm{gudB}$ and roc $G$ were deleted, $\gamma$-PGA production of $5 \mathrm{~g} / \mathrm{L}$ was obtained, which was about $38 \%$ higher than control [61]. In B. licheniformis WX-02, the genes responsible for NADPH regeneration, such as $z w f$, were overexpressed, resulting in $35 \%$ higher $\gamma$-PGA yield than control. The production of various polysaccharides can act as contaminants and cause difficulty in the $\gamma$-PGA purification [62]. In B. amyloliquefaciens NK-E5, the genes responsible for the production of levan and lipopolysaccharides were excised, resulting in increased PGA purity from $78 \%$ to $95 \%$, although the production remained the same as control. Similarly, in B. amyloliquefaciens NK-E7, the deletion of the genes responsible for by-product formation, such as pta, enhanced $\gamma$-PGA production by $11 \%$ [60]. In another study, genes related to antibiotic production such as itu and $\operatorname{srf}$ were deleted, aiding in $36 \%$ of the $\gamma$-PGA yield. The carbon flux was manipulated in B.licheniformis WX-02 by replacing glpFK promoter with different promoters, causing an increasing utilization of glycerol ( $\sim 31 \%$ more) followed by enhanced $\gamma$-PGA production. The increase in the $\gamma$-PGA production results in increased broth viscosity, followed by a decrease in the oxygen mass transfer rate. This problem can be tackled by the insertion of bacterial hemoglobin gene such as the $v g b$ gene. Insertion of $v g b$ gene in B. amyloliquefaciens LL3 via a plasmid or chromosomal route enhanced $\gamma$-PGA production to about $30 \%$ [63]. Further deleting the gene such as mreB responsible for maintaining cell morphology and cell wall synthesis elevated $\gamma$-PGA production to 57\% [64]. Apart from Bacillus strain, several heterologous expression of $\operatorname{pgs}_{s} B A$ genes was done in Corynebacteriumglutamicumand Escherichia coli which resulted in $\gamma$-PGA production in C. glutamicum with a yield of $0.7 \mathrm{~g} / \mathrm{L}$ in a medium devoid of glutamic acid [53, 65, 66]. Recently, Gao et al. used different metabolic engineering strategies wherein they partly blocked metabolic pathways by deleting $f a d R, l_{s} C$, aspB, pckA, 
Table 2 Production of $\gamma$-PGA by Bacillus strains using different synthetic medium

\begin{tabular}{|c|c|c|c|c|c|c|}
\hline Bacillus strain & Major nutrients & $\begin{array}{l}\text { Time } \\
\text { (h) }\end{array}$ & $\begin{array}{l}\text { Temp. } \\
\left({ }^{\circ} \mathrm{C}\right)\end{array}$ & $\begin{array}{l}\text { Yield } \\
(\mathrm{g} / \mathrm{L})\end{array}$ & $\begin{array}{l}\text { Productivity } \\
\text { (g/L/h) }\end{array}$ & Ref. \\
\hline B. licheniformis A35 & Glucose, ammonium chloride & 120 & 30 & 11.1 & 0.09 & {$[88]$} \\
\hline B. licheniformis ATCC 9945A & Glutamic acid, glycerol, citric acid, $\mathrm{NH}_{4} \mathrm{Cl}$ & 141 & 37 & 17 & 0.12 & {$[37]$} \\
\hline B. licheniformis ATCC 9945a & Glutamic acid, glycerol, citric acid, $\mathrm{NH}_{4} \mathrm{Cl}$ & 96 & 37 & 20.5 & 0.21 & {$[89]$} \\
\hline B. licheniformis ATCC 9945A & Glutamic acid, glycerol, citric acid, $\mathrm{NH}_{4} \mathrm{Cl}$ & 28 & 37 & 23.2 & 0.82 & {$[90]$} \\
\hline B. licheniformis CCRC 12826 & L-glutamic acid, Citric acid, Glycerol, $\mathrm{NH}_{4} \mathrm{Cl}$ & 96 & 37 & 19.8 & 0.2 & {$[32]$} \\
\hline B. licheniformis WBL-3 & Glutamic acid, glycerol, citric acid, $\mathrm{NH}_{4} \mathrm{Cl}$ & 88 & 37 & 29.4 & 0.33 & {$[35]$} \\
\hline B. licheniformis SAB-26 & Glucose, glycerol, citric acid & 48 & 37 & 33.5 & 0.69 & {$[42]$} \\
\hline B. licheniformis NCIM 2324 & $\begin{array}{l}\text { L-glutamic acid, citric acid, glycerol,L-Glutamine, } \\
\alpha \text {-Ketoglutaric Acid, }\end{array}$ & 96 & 37 & 35.75 & 0.37 & {$[34]$} \\
\hline B. licheniformis WX-02 & Glutamic acid, glucose, citric acid, $\mathrm{NH}_{4} \mathrm{Cl}$ & 96 & 37 & 13.86 & 0.14 & {$[36]$} \\
\hline B. licheniformis A13 & Glucose, yeast extract, $\mathrm{NH}_{4} \mathrm{Cl}$ & 72 & 37 & 28.2 & 0.39 & {$[43]$} \\
\hline B. licheniformis CGMCC3336 & Glucose, sodium glutamate, yeast extract & 34 & 37 & 35 & 1.02 & [91] \\
\hline B. licheniformis $\mathrm{P}-104$ & Glucose, sodium glutamate, sodium citrate & 39 & 37 & 41.6 & 1.06 & {$[92]$} \\
\hline B. licheniformis NCIM 2324 & Sugarcane juice, glutamate, yeast extract & 40 & 35 & 36.5 & 0.91 & {$[93]$} \\
\hline B. licheniformis TISTR 1010 & Glucose, citric acid, $\mathrm{NH}_{4} \mathrm{Cl}$ & 96 & 37 & 27.5 & 0.28 & {$[45]$} \\
\hline B.licheniformis CGMCC 2876 & Tri-sodium citrate, glucose, L-glutamic acid, glycerol, $\mathrm{NH}_{4} \mathrm{Cl}$ & 20 & 37 & 21.8 & 1.09 & {$[33]$} \\
\hline B. licheniformis TISTR 1010 & Glucose, citric acid, tween- $80, \mathrm{NH}_{4} \mathrm{Cl}$ & 43 & 37 & 39.9 & 0.92 & {$[44]$} \\
\hline Bacillus licheniformisA14 & Glucose, citric acid, monosodium glutamate & 48 & 37 & 37.8 & 0.78 & {$[94]$} \\
\hline $\begin{array}{l}\text { Bacillus licheniformisLMG } \\
7559\end{array}$ & Sodium glutamate, glucose, $\left(\mathrm{NH}_{4}\right)_{2} \mathrm{SO}_{4}$ & 72 & 37 & 0.5 & 0.0069 & {$[95]$} \\
\hline B. subtilis IF0333 & L-glutamic acid, citric acid, ammonium sulfate & 40 & 37 & 10.04 & 0.25 & {$[19]$} \\
\hline B. subtilis F-2-01 & Veal infusion broth, glucose, L-glutamic acid & 94 & 37 & 48 & 0.51 & {$[96]$} \\
\hline B. subtilis TAM-4 & Fructose, ammonium chloride & 96 & 30 & 22.1 & 0.23 & [39] \\
\hline B. subtilis $\mathrm{MR}-141$ & Sodium glutamate, maltose, soy sauce & 96 & 40 & 35 & 0.36 & {$[26]$} \\
\hline B. subtilis var. chungkookjang & Sucrose, $\left(\mathrm{NH}_{4}\right)_{2} \mathrm{SO}_{4}$, L-glutamic acid & 120 & 30 & 13.5 & 0.11 & {$[49]$} \\
\hline B. subtilis IFO 3335 & Glycerol, citric acid, glutamic acid & 30 & 37 & 23 & 0.76 & {$[97]$} \\
\hline B. subtilis $\mathrm{C} 1$ & Glutamic acid, glycerol, citric acid, $\mathrm{NH}_{4} \mathrm{Cl}$ & 144 & 37 & 21.4 & 0.14 & {$[98]$} \\
\hline B. subtilis NX-2 & Glucose, L-glutamic acid, yeast extract & 24 & 37 & 30.2 & 1.25 & {$[99]$} \\
\hline B. subtilis ZJU-7 & Sucrose, tryptone,L-glutamic acid & 24 & 37 & 58.2 & 2.42 & {$[100]$} \\
\hline B. subtilis $\mathrm{NX}-2$ & Glucose,glutamic-acid,yeast extract & 48 & 32.5 & 28.42 & 0.59 & {$[31]$} \\
\hline B. subtilis CGMCC 0833 & Glucose, glutamate, $\left(\mathrm{NH}_{4}\right)_{2} \mathrm{SO}_{4}$, Tween 80 & 48 & 32.5 & 34.4 & 0.71 & {$[16]$} \\
\hline B. subtilis ZJU-7 & Glutamic acid, glucose, tryptone & 64 & 37 & 54 & 0.84 & [101] \\
\hline B. subtilis NX-2 & L-glutamate, glucose, $\mathrm{NH}_{4} \mathrm{Cl}$ & 120 & 32.5 & 42 & 0.35 & {$[102]$} \\
\hline B. subtilis NX-2 & Glucose, glutamate, glycerol & 48 & 32.5 & 31.7 & 0.66 & {$[103]$} \\
\hline B. subtilisnatto ATCC 15245 & Glutamic acid, sucrose, ammonium sulphate & 96 & 37 & 28 & 0.29 & {$[25]$} \\
\hline B. subtilis CGMCC1250 & Glucose, glutamate, yeast extract & 46 & 37 & 101 & 2.19 & {$[24]$} \\
\hline B. subtilis NX-2 & Glucose, glutamate, $\left(\mathrm{NH}_{4}\right)_{2} \mathrm{SO}_{4}$ & 72 & 32 & 40.5 & 0.56 & [104] \\
\hline B.subtilis R 23 & Glucose,citric acid, L-glutamic acid, $\mathrm{NH}_{4} \mathrm{Cl}$ & 48 & 37 & 25.38 & 0.52 & {$[18]$} \\
\hline B. subtilis 2063 & Glucose, citric acid, L-glutamic acid, $\mathrm{NH}_{4} \mathrm{Cl}$ & 96 & 37 & 21.42 & 0.22 & {$[105]$} \\
\hline B.subtilis D7 & L-glutamate, glucose. Yeast extract & 72 & 30 & 4.7 & 0.06 & {$[17]$} \\
\hline B. subtilis D7 & Glutamic acid, mannitol, yeast extract & 36 & 35 & 24.93 & 0.69 & {$[106]$} \\
\hline B. subtilis MJ80 & L-glutamic acid, glycerol, citric acid, starch,urea & 72 & 37 & 68.7 & 0.95 & {$[21]$} \\
\hline B. subtilis NX-2 & Glucose, glutamate, $\left(\mathrm{NH}_{4}\right)_{2} \mathrm{SO}_{4}$ & 57 & 32 & 71.21 & 1.24 & [107] \\
\hline B. subtilisBL53 & Glutamic acid, glycerol, citic acid, $\mathrm{NH}_{4} \mathrm{Cl}$ & 24 & 37 & 23.5 & 0.97 & {$[22]$} \\
\hline B. subtilis GXG-5 & Glucose, ammonium nitrate & 34 & 50 & 19.5 & 0.57 & {$[41]$} \\
\hline B. methylotrophicus SK19.001 & Glycerol,sodium citrate, peptone & 66 & 37 & 35.34 & 0.53 & {$[108]$} \\
\hline B. methylotrophicus & mannitol, monosodium glutamate, peptone & 96 & 37 & 36 & 0.37 & {$[38]$} \\
\hline B. amyloliquefaciens LL3 & Sucrose, $\left(\mathrm{NH}_{4}\right)_{2} \mathrm{SO}_{4}$ & 44 & 37 & 4.36 & 0.09 & {$[60]$} \\
\hline B. velezensis NRRL B - 23189 & Molasses, citric acid, ammonium sulphate & 72 & 27 & 4.82 & 0.06 & [109] \\
\hline $\begin{array}{l}\text { Bacillus. sp. RKY3 KCTC } \\
\text { 10412BP }\end{array}$ & Glutamic acid, glycerol, citric acid, $\mathrm{NH}_{4} \mathrm{Cl}$ & 48 & 38 & 28.4 & 0.59 & {$[110]$} \\
\hline $\begin{array}{l}\text { Bacillus.sp. RKY3 KCTC } \\
\text { 10412BP }\end{array}$ & Glutamic acid, glycerol, citric acid, $\mathrm{NH}_{4} \mathrm{Cl}$ & 24 & 38 & 48.7 & 2.02 & [111] \\
\hline Bacillus siamensis SB1001 & Sucrose, L-glutamic acid, $\mathrm{NH}_{4} \mathrm{Cl}$ & 24 & 37 & 25.22 & 1.02 & [112] \\
\hline B. sonorensis 44 & Glycerol, yeast extract, $\alpha$-ketoglutaric acid & 72 & 30 & 11.84 & 0.16 & [113] \\
\hline
\end{tabular}

$\operatorname{pro} A B, \operatorname{roc} G$, and $g u d B$. Furthermore, the srf and itu operons were deleted, and the NADPH level was improved by regulating the expression of $p g i$ and $g n d A$. The final engineered strain NK-A6 yielded $7.5 \mathrm{~g} / \mathrm{l} \gamma$-PGA, with a twofold increase 
Table 3 Economical production of $\gamma$-PGA using different wastes

\begin{tabular}{|c|c|c|c|c|c|c|c|}
\hline $\begin{array}{l}\text { Bacillus } \\
\text { strain }\end{array}$ & Wastes & Additional nutrient & $\begin{array}{l}\text { Time } \\
\text { (h) }\end{array}$ & $\begin{array}{l}\text { Temperature } \\
\left({ }^{\circ} \mathrm{C}\right)\end{array}$ & $\begin{array}{l}\text { Yield } \\
(\mathrm{g} / \mathrm{L})\end{array}$ & $\begin{array}{l}\text { Productivity } \\
\text { (g/L/h) }\end{array}$ & Ref. \\
\hline $\begin{array}{l}\text { B. subtilis } \\
\text { CCTCC202048 }\end{array}$ & Swine manure, soy bean cake & Glutamic acid, citric acid & 48 & 37 & 45 & 0.9 & {$[11]$} \\
\hline B. subtilis NX-2 & Cane molasses & Glutamate, $\left(\mathrm{NH}_{4}\right)_{2} \mathrm{SO}_{4}$ & 96 & 32 & 51.1 & 0.53 & {$[27]$} \\
\hline B. subtilisHB-1 & Corncob fibrehydrolysate & L-glutamate and yeast extract & 40 & 37 & 24.92 & 0.62 & {$[30]$} \\
\hline B. subtilis NX-2 & Rice straw hydrolysate & Glutamate, $\left(\mathrm{NH}_{4}\right)_{2} \mathrm{SO}_{4}$ & 90 & 32 & 73 & 0.81 & [29] \\
\hline B. subtilisZC-5 & chicken manure & $\begin{array}{l}\text { Crude extract of glutamic acid, } \\
\text { sodium glutamate waste liquor }\end{array}$ & 48 & 37 & 65.7 & 1.3 & {$[20]$} \\
\hline B. subtilis A3 & fish meal wastewater & glucose, L-glutamate & 48 & 37 & 25 & 0.52 & {$[23]$} \\
\hline $\begin{array}{l}\text { B. licheniformis } \\
9945 \mathrm{a} .\end{array}$ & Goose feather hydrolysate & $\begin{array}{l}\text { L-glutamate, tri-sodium citrate } \\
\text { dihydrate, glycerol }\end{array}$ & 48 & 30 & 5.4 & 0.11 & {$[8]$} \\
\hline $\begin{array}{l}\text { B. licheniformis } \\
\text { WX-02 }\end{array}$ & Paper waste hydrolysate & $\begin{array}{l}\text { Glucose, sodium glutamate, } \\
\text { sodium citrate }\end{array}$ & 36 & 37 & 6.46 & 0.17 & {$[67]$} \\
\hline B. sp. SJ-10 & $\begin{array}{l}\text { Macroalgae } \\
\text { (Ulva) }\end{array}$ & Sucrose, L-glutamate & 48 & 37 & 6.29 & 0.13 & [9] \\
\hline $\begin{array}{l}\text { B. amyloliquefaciens } \\
\mathrm{C} 1\end{array}$ & $\begin{array}{l}\text { Dairy manure compost, monosodium } \\
\text { glutamate production residues }\end{array}$ & citric acid & 48 & 37 & 60 & 1.25 & {$[12]$} \\
\hline $\begin{array}{l}\text { B. amyloliquefaciens } \\
\text { JX6 }\end{array}$ & Corn stalk, Soybean meal & $\begin{array}{l}\text { Industrial monosodium } \\
\text { glutamate }\end{array}$ & 72 & 37 & 112.82 & 1.56 & [114] \\
\hline B. siamensisIR10 & molasses & L-Glutamic acid, $\mathrm{NH}_{4} \mathrm{Cl}$ & 20 & 37 & 45.42 & 2.02 & [115] \\
\hline
\end{tabular}

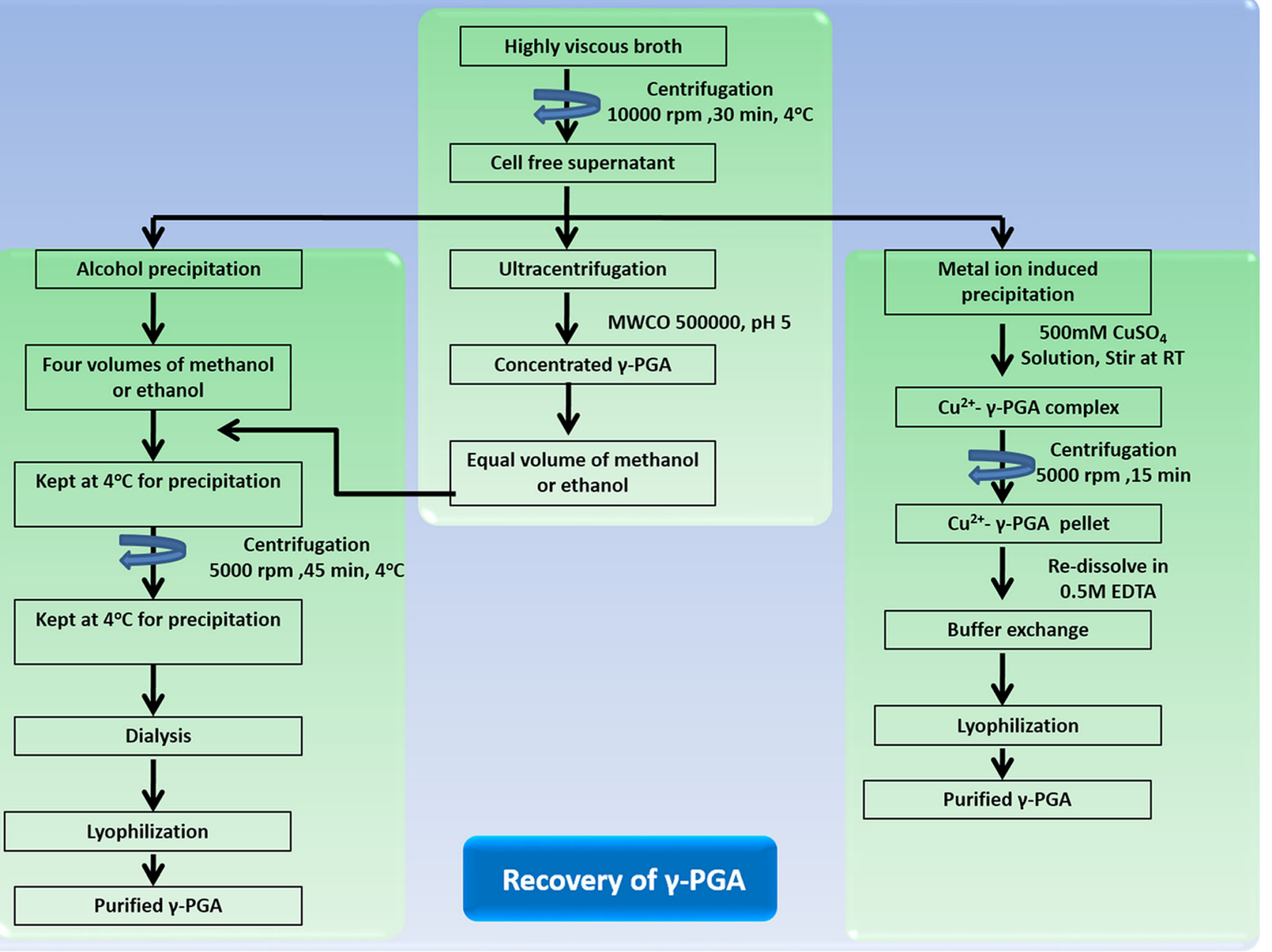

Fig. 3 Methods for efficient recovery of $\gamma$-PGA [68] 
yield in comparison to B. amyloliquefaciens LL3 strain [46]. Despite all these metabolic engineering approaches, wild-type strains remain the potent and highest producers for $\gamma$-PGA.

\subsection{Downstream process for recovery of $\mathrm{Y}$-PGA}

The downstream process is one of the main challenges for the scale-up of $\gamma$-PGA production with high purity. Various downstream processes are crucial for the recovery and characterization of $\gamma$-PGA synthesized in the fermentation medium. For efficient recovery of $\gamma$-PGA, three different strategies have been executed: precipitation (alcohol and metal ioninduced) and ultrafiltration (Fig. 3).

\subsubsection{Precipitation}

The precipitation process is the conversion of desired products (chemical substance) into a solid form or in crystals from a solution by converting the substance into an insoluble form. Alcohol precipitation is a standard method used for $\gamma$-PGA recovery. Alcohols such as methanol or ethanol are usually used for the precipitation of $\gamma$-PGA from the fermented broth. In this method, the fermentation broth is pellet down (centrifuged at 10,000 rpm for $30 \mathrm{~min}$ ). Furthermore, four volumes of ice-cold methanol or ethanol are added to the cell-free supernatant and kept at $4^{\circ} \mathrm{C}$ for $12 \mathrm{~h}[34,42]$. In the final step, centrifugation ( $5000 \mathrm{rpm}$ for $45 \mathrm{~min}$ ) is carried out to obtain crude $\gamma$-PGA, followed by dissolving it in distilled water. The aqueous $\gamma$-PGA solution is desalted by dialysis (Mw $14 \mathrm{kDa}$ cut-off) with multiple water exchanges for 12 $\mathrm{h}$, and finally purified $\gamma$-PGA is achieved by lyophilization [34].

The other precipitation method is metal precipitation, where different metal ions such as $\mathrm{CuSO}_{4}, \mathrm{FeCl}_{3}, \mathrm{AlCl}_{3}$, and $\mathrm{MnSO}_{4}$ were used and optimized for $\gamma$-PGA precipitation in aqueous solution as well as from the fermented broth. In an aqueous solution, the addition of $\mathrm{CuSO}_{4}$ formed a pale bluish-green precipitate with an optimum concentration of $50 \mathrm{mM}$. In the case of fermented broth supplemented with $50 \mathrm{mM} \mathrm{CuSO}_{4}$ solution, no precipitation was observed; however, at $500 \mathrm{mM}$ concentration, up to $95 \%$ recovery was obtained. The tenfold difference in the concentration of $\mathrm{CuSO}_{4}$ for precipitation may be because of other metal ions present in the fermentation broth that may bind to the anionic sites of $\gamma$-PGA. The $\mathrm{Cu}^{2+}-\gamma$-PGA complex so formed is collected by centrifugation and re-dissolved in EDTA, followed by water exchange and lyophilization to achieve purified $\gamma$ -

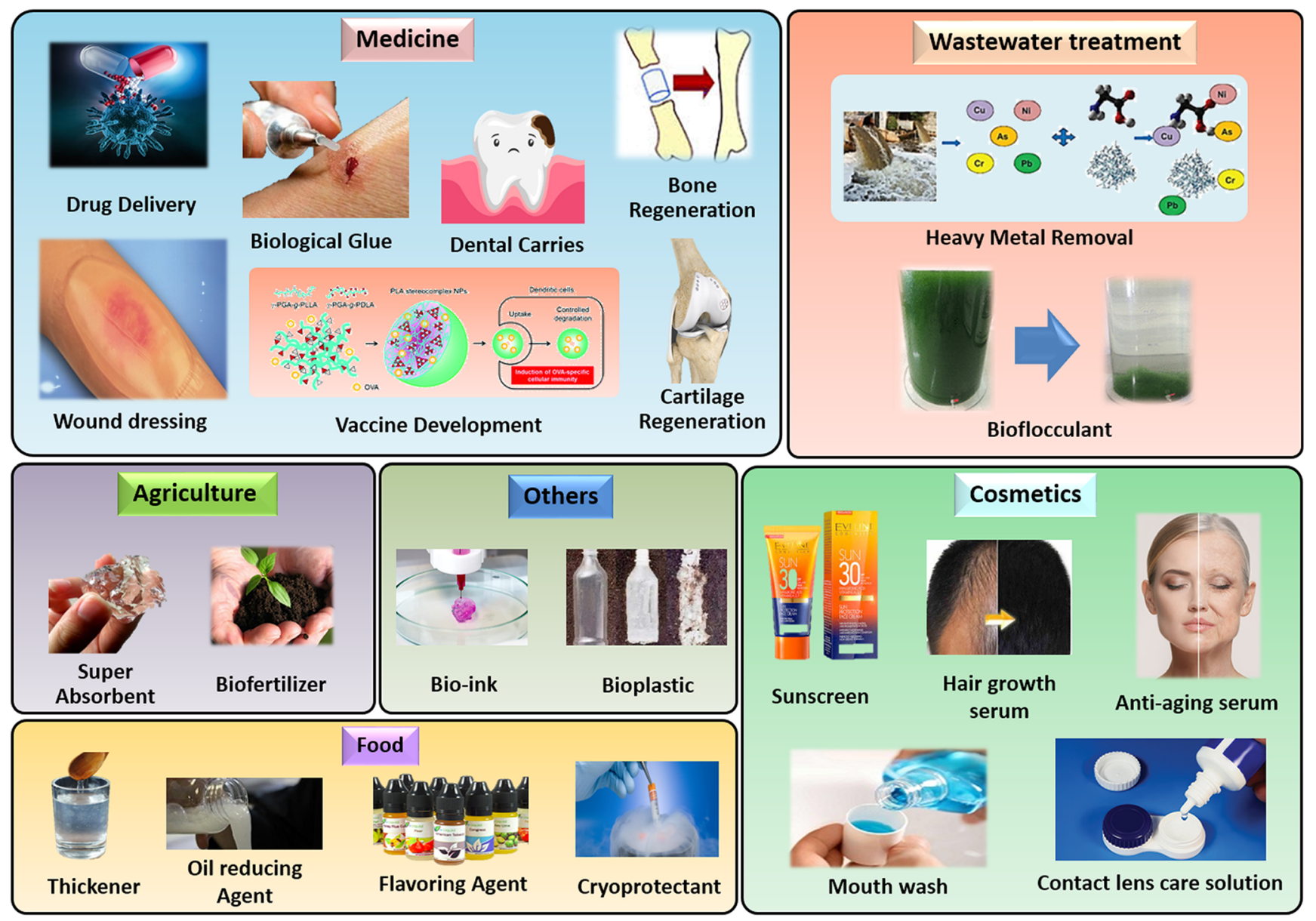

Fig. 4 Various $\gamma$-PGA products with potential industrial applications $[6,72]$ 
Table 4 Application of $\gamma$-PGA in various fields

Field Application Description

Agriculture Super-absorbent

Biofertilizer

Wastewater treatment

Wound healing

Dental caries

Bone regeneration

Cartilage regeneration

Rheumatoid arthritis (RA)

Drug delivery

Vaccine

Biological glue

Others

$$
\begin{aligned}
& \text { Food packing } \\
& \text { biomaterial/Bioplas- } \\
& \text { tic }
\end{aligned}
$$

Bio-ink

Cosmetics
Description

boll numbers per plant, length of cotton fibre, stem diameter, plant height.

To retain water in the soil for a longer period, reduce the soil water infiltration.

Boost fertility of the soil, increase utilization of essential minerals, enhance plant growth-promoting bacteria.

Ability to remove $\mathrm{Cr}^{3+,} \mathrm{Cu}^{2+,} \mathrm{Pb}^{2+}$ and $\mathrm{Ni}^{2+}$ at acidic $\mathrm{pH}$ using novel magnetic nanoparticles comprising of $\gamma$-PGA and $\mathrm{Fe}_{3} \mathrm{O}_{4}$.

$\gamma$-PGA as a cation exchanger for removal of mercury.

Nano-membrane technology consisting of $\gamma$-PGA nanoparticles and ultrafiltration techniques for [121] the effective removal of lead contaminants.

Soil washing with $\gamma$-PGA can remove $56.5 \%, 53.1 \%, 50 \%, 74.3 \%$ of $\mathrm{Ni}, \mathrm{Zn}, \mathrm{Cr}$ and $\mathrm{Cu}$, respectively, from contaminated sites.

Enhanced removal of cesium from radioactive wastewater using $\gamma$-PGA.

$\gamma$-PGA at $0.8 \mathrm{ppm}$ shows high flocculating ability,so it can replace polyacrylamide from sugarcane industry.

Scaffold comprising of $\gamma$-PGA and PLA could efficiently accelerate re-epithelialization by infil- [124] tration of fibroblast and keratinocytes.

$\mathrm{Ag} / \gamma$-PGA composite showed accelerated wound closure by preventing moisture evaporation and [125] better water absorption.

A versatile $\gamma$-PGA/gelatin hydrogel crosslinked with proanthocyanidins have shown to boost wound recovery by its swelling, antioxidant and fibroblast growth properties.

$\gamma$-PGA/chitosan polyelectrolytic complex could reduce inflammation and enhance epithelial cell [127] reestablishment, thereby effective healing.

$\gamma$-PGA as an attractive alternative to hyaluronic acid in corneal wound closure.

Promotes re-mineralization for protection of enamel.

Electrospunfibres of $\gamma$-PGA/ $\beta$-tricalcium phosphate can be an interesting replacement material for bone regeneration as it exhibits high cell adhesion, osteogenesis, alkaline phosphatase activity aiding in bone deformity repair.

Microsphere developed from $\gamma$-PGA/chitosan showed propagation and attachment of chondrocytes forming fibrous tissue.

$\gamma$-PGA hydrogel encapsulated mesenchymal stem cell could re-establish cartilage in auricular defective rabbit.

$[130-132]$

A unique nano-drug carrier was developed using $\gamma$-PGA, which could reduce the toxic nature of [134] triptolide, thereby improving its efficacy for RA treatment.

$\gamma$-PGA can quench osteoclastogenesis as well as decrease the destruction of bones in a mouse model

A nanoconjugate derived from $\gamma$-PGA and cisplatin exhibited improved antitumor activity against liver and breast cancer with reduced toxicity both in vivo and in vitro.

A self-assembling nanoparticle comprising of $\gamma$-PGA and chitosan could be used to deliver anticancer drug with high efficacy in ovarian cancer cells.

A unique thermos-responsive microgel derived from $\gamma$-PGA/hydroxypropyl cellulose for oral delivery of insulin in a controlled manner.

A light-inducible hydrogel based on $\gamma$-PGA/collagen could be used for controlled release of DOX, [140] serving as an effective platform for drug delivery.

A novel oral delivery platform for anti-diabetes was developed consisting of $\gamma$-PGA conjugated with an inhibitor of $\mathrm{Na}+$ /glucose cotransporter(phloridzin), which could decrease the hyperglycemic effect with high efficacy.

Nanoparticle derived from $\gamma$-PGA has the potential to evoke cellular and humoral immunity serve as the basis of vaccination for the treatment of HIV, various cancers, Japanese encephalitis virus.

$\gamma$-PGA has been used as an attractive substitute for fibrin glue for sealing air leakage after lung surgery.

Chemical modification of $\gamma$-PGA to form bioplastic with excellent properties such as resistant to acid and alkali, antimicrobial activity, hydrophobic and biodegradability.

Composite of $\gamma$-PGA /Poly lysine can be a suitable probiotic carrier with application in edible food [145] packaging materials. Chemical modification of $\gamma$-PGA to form bioplastic with excellent properties such as resistant to acid and alkali, antimicrobial activity, hydrophobic and biodegradability.

$\gamma$-PGA/chitosan bio-ink has a remarkable cell survival rate inside3D bio-printed hydrogel.

-PGA formulation in next-generation sunscreens for protection against UVA and UVB. 
Table 4 (continued)

\begin{tabular}{|c|c|c|c|}
\hline Field & Application & Description & Ref. \\
\hline & Mouthwash & $\begin{array}{l}\gamma \text {-PGA can be used in mouthwash formulations as a replacement for alcohol since it is } \\
\text { non-irritable, nontoxic and can inhibit E.coli, S.aureus with high efficacy. }\end{array}$ & [148] \\
\hline & Hair growth promoter & $\begin{array}{l}\gamma \text {-PGA with UHMW has shownto induce hair growth by acting on the anagenic stage of the hair } \\
\text { growth cycle and suppressing the 5-alpha reductase activity. }\end{array}$ & [149] \\
\hline & & $\begin{array}{l}\text { Nano-formulation based on } \gamma \text {-PGA hydrogel and herbal extract can enhance the size of the hair } \\
\text { bulb and effectively deliver growth metabolites to the hair follicles. }\end{array}$ & {$[150]$} \\
\hline & $\begin{array}{l}\text { Contact lens care } \\
\text { solution }\end{array}$ & $\gamma$-PGA as an effective cleaning agent of ionic contact lenses with lubricating property. & [151] \\
\hline \multirow[t]{4}{*}{ Food } & Oil reducing agent & $\begin{array}{l}\text { Oil uptake was reduced by five folds in doughnuts containing } 0.2 \mathrm{~g} \text { of } \gamma \text {-PGA/g dough and also } \\
\text { had a better appearance and taste than regular doughnuts. }\end{array}$ & {$[34]$} \\
\hline & Thickener & Increases viscosity in fruit juices and sport drinks. & {$[5]$} \\
\hline & $\begin{array}{l}\text { Bitterness relieving } \\
\text { agent }\end{array}$ & The addition of $\gamma$-PGA to compounds having a bitter taste such as caffeine relieved its bitterness. & {$[152]$} \\
\hline & Cryoprotectant & Act as a better antifreeze agent than sucrose in protecting probiotic bacteria. & [153] \\
\hline
\end{tabular}

PGA. The recovery percent of $\gamma$-PGA using metal ion-induced precipitation is $85 \%$ compared to alcohol precipitation, $82 \%$. Similarly, the co-precipitation of proteins is just $3 \%$ with this strategy compared to $50 \%$ using alcohol precipitation, indicating its higher selectivity $[5,67,68]$.

\subsubsection{Ultrafiltration}

Another effective recovery approach for $\gamma$-PGA is ultrafiltration, which reduces the use of a solvent in the downstream process. It can retain macromolecules in the solution with the help of hollow fiber membranes aiding in concentrating high molecular weight $\gamma$-PGA $[69,70]$. In this process, the $\gamma$-PGA was centrifuged (10000 rpm for $30 \mathrm{~min}$ ), and the cell-free supernatant was then concentrated using ultracentrifugation. At the mol. wt. Cut-off (MWCO) of the membrane 30 to 100 $\mathrm{kDa}$, the loss of $\gamma$-PGA was negligible, but the flow rate was low. However, with MWCO of $500 \mathrm{kDa}$, the flux was comparatively higher, with only $3 \%$ loss in $\gamma$-PGA. For ultrafiltration, the $\mathrm{pH}$ plays a crucial role in concentrating the cellfree supernatant with a considerable loss at lower $\mathrm{pH}$ due to a change in the conformation of $\gamma$-PGA. At lower $\mathrm{pH}$, the hydrodynamic radius of $\gamma$-PGA decreases due to the change from random coil structure to helical form, enhancing the membrane permeability. Therefore, at $\mathrm{pH} 3$, the concentrate had $110 \mathrm{~g} / \mathrm{L}$ of $\gamma$-PGA, whereas, at $\mathrm{pH} 5$, the value decreased to $60 \mathrm{~g} / \mathrm{L}$. With this strategy, the amount of alcohol utilized for $\gamma$-PGA precipitation can be significantly reduced $[5,71]$.

\section{Application of $\mathrm{Y}-\mathrm{PGA}$}

Due to the remarkable properties of $\gamma$-PGA, it has been chosen as a suitable candidate for applications in various fields as medicine (bone regeneration, dental carries, wound dressing, drug delivery, vaccine development, bio-glue), agriculture (biofertilizer, super-absorbent), wastewater treatment (bioflocculants, metal removal), cosmetics (anti-ageing,mouth wash, sunscreen lotion), food industries (flavouring agent, thickener, packaging material), etc. as summarized in Fig. 4 and Table $4[6,72]$.

\section{Challenges and strategies in the commercialization of $\mathrm{Y-PGA}$}

Recently, the interest in the wider commercialization of $\gamma$ PGA has been gaining immense attention due to its phenomenal properties and its use in diverse applications. Since Bacillus species are the most potent producers of $\gamma$-PGA, it is a boon for biotechnological industries as most of the Bacillus species are considered as GRAS (Generally Regarded As Safe) organisms [73]. The major bottleneck in $\gamma$-PGA production is the high cost associated with the media components. A probable solution is to reduce the overall production cost by using waste that can replace all the nutrients required for $\gamma$ - PGA biosynthesis [29]. As there is enormous potential in India and European countries for the valorization of surplus waste, we can direct the waste for economic and

Fig. 5 Microbial genome editing tools for $\gamma$-PGA production: A) Chromosomal integration for inserting new genes in the microbial genome. B) Optimization of the metabolic pathway by inserting various combinations of modules. C) Cross-lapping-in vitro assembly (CLIVA) for inserting multiple modules in vector. D) CRISPR/Cas9-mediated genome editing. E) CRISPRi/CRISPRa-mediated transcriptional regulation of genes used for the downregulation(interference) or upregulation (activation) of specific genes. F) Eukaryotic MultiplexAutomated genome engineering (eMAGE) used for achieving specific chromosomal mutations with high efficiency. G) RNAi-mediated transcriptional regulation tool used to cleave specific mRNA sequences $[82,86,87]$ 


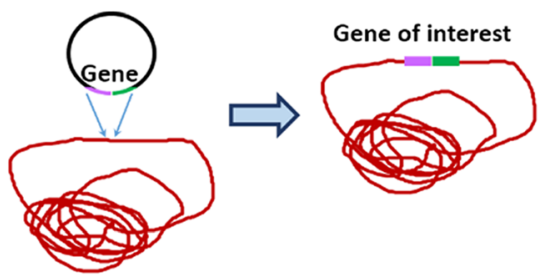

Chromosomal integration b Modules

A

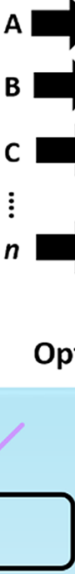

$\rightarrow 00$

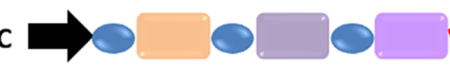

$\vdots$
Promoter library

RBS library

Terminator

MEP/MVA

pathway genes

C

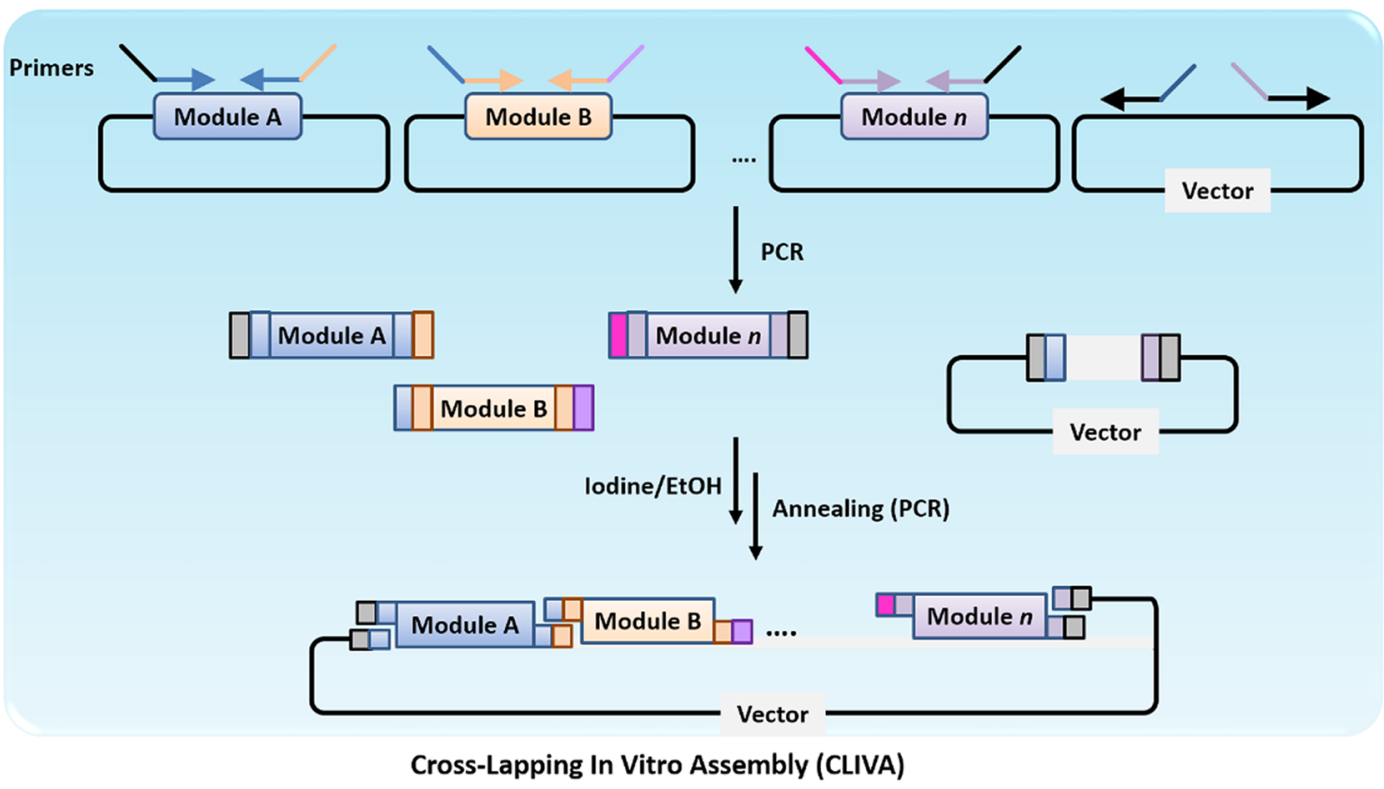

d

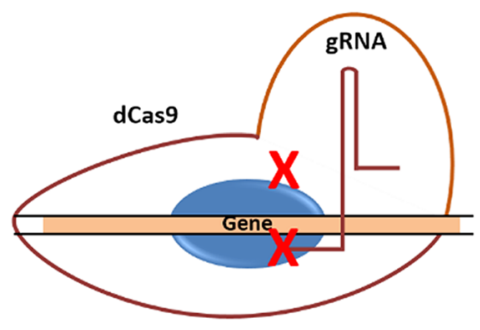

CRISPR/CAS9-mediated

genome editing

f

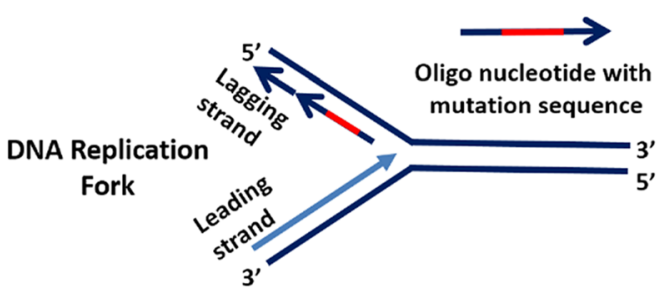

Eukaryotic Multiplex Automated Genome Engineering (eMAGE) e

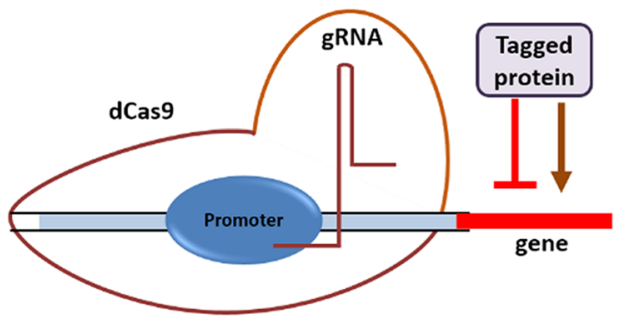

CRISPRi/CRISPRa

g Targeted Enzyme/protein

mRNA strand

RNAi Technique 
feasible production of $\gamma$ - PGA. However, the waste selected for $\gamma$-PGA production must be accessible throughout the year to keep the process technology in place. Extensive research has been conducted to reduce the production cost of $\gamma$-PGA, such as the use of lignocellulosic biomass, waste manure, macroalgae, goose feathers, and fishmeal wastewater (Table 3) [5, 23]. Excessive accumulation of such waste will have a negative environmental impact, and thus it is essential to valorize this surplus waste into a value-added commodity, thereby strengthening our economic sustainability. However, these wastes require either acid/alkali pretreatment or supplementation with additional nutrients to be used in the production medium, further adding to the cost [74]. Thus, there is an utmost need for a waste that is multi-nutritious and does not require any pretreatment. Such a multi-nutritious waste medium that can serve as a source of carbon, glutamic acid, and nitrogen without the supplementation of any additional nutrients and pretreatment will help in reducing the overall cost of the process [75]. Another way to reduce the production cost is the implementation of a mixed culture strategy. The fermentation involving mixed culture has several advantages over pure culture, including higher yield as well as efficient and better utilization of diverse wastes. B. subtilis have been cocultured with C.glutamicum using glucose and sucrose as a mixed carbon source, thereby shortening the fermentation time and reducing the production cost [76]. The production cost of $\gamma$-PGA using L-glutamic acid-dependent strains are higher as compared to L-glutamic acid independent strains due to external supply of L-glutamic acid in the fermentation medium. The strains of C.glutamicum are well-known for the production of glutamic acid from different wastes. Thus, in the case of L-glutamic acid-dependent strains, a stable association between the strains of C.glutamicum and Bacillus species could be used for enhanced $\gamma$-PGA production in the fermentation medium devoid of glutamic acid $[15,66,77,78]$. The cost of $\gamma$-PGA is solely based on the cost of the production media as well as the productivity of the $\gamma$-PGA producing strains [79]. The lower the productivity of $\gamma$-PGA, the higher will be the cost of production, ultimately resulting in increased cost of $\gamma$-PGA. Thus, lower production, as well as productivity of $\gamma$-PGA, is another hurdle that can be addressed by goalbased screening for $\gamma$-PGA producers. For example, isolation and screening of osmophilic strains that could produce $\gamma$ PGA at higher sugar concentration will aid in higher production and productivity in a batch fermentation [5]. Similarly, extremophilic bacteria such as halophiles can be explored for their ability to produce $\gamma$-PGA. Since the presence of $\mathrm{NaCl}$ is known to reduce the molecular weight of $\gamma$-PGA [36], it would be worth exploring the characteristic of $\gamma$-PGA produced by different halophiles at a high salt concentration. Their ability to grow at higher salt concentrations will also reduce the risk of contamination in non-sterilized fermentation media. On the other hand, hyperthermophilic strains can also be screened for $\gamma$-PGA production to extract $\gamma$-PGA with higher thermo-stability [80]. The productivity of $\gamma$-PGA further can be increased by metabolic engineering strategies. The advancement in emerging tools, knowledge, and technologies in synthetic biology and protein engineering can be combined to develop combinatorial engineering strategies to boost carbon flux for the microbial production of $\gamma$-PGA. For achieving a higher titre of $\gamma$-PGA, new enzyme screening, novel pathway discovery, conjugation of multiple pathways from district systems could be used. The traditional homologous recombination and chromosomal integration techniques, the modular control systems [81-83], the pathway assembly methodsCross-Lapping-In Vitro assembly (CLIVA) [84], and the newly emerging techniques/tools for gene replacement/editing e.g.CRISPR/CAS9 [85] (Fig. 5) would boost the developments in the biosynthesis of $\gamma$-PGA in native and heterologous host systems. The cell growth pattern can be manipulated by excising genes involved in binary fission such as $\operatorname{mic} C$ and $\min D$ resulting in multiple fission. This approach will increase the biomass concentration within a short period, thereby reducing the time required for the maximum production of $\gamma$ - PGA, ultimately increasing the productivity [53]. Similarly, the genes involved in the byproduct formation, such as polysaccharides, can be knocked out by biotechnological tools such as CRISPR/CAS9 [85]. This will direct the carbon flux entirely towards $\gamma$ - PGA biosynthesis, thereby increasing the $\gamma$ - PGA production with high purity.

\section{Conclusion and future prospects}

In conclusion, $\gamma$-PGA is a naturally occurring biopolymer made up of repeating units ofL/D-glutamic acid, or both. Due to its biodegradable, edible, non-immunogenic, nontoxic properties, it has been applied in various industrial sectors. Since its discovery in 1937, to date, remarkable research has been carried out by different research groups around the globe. Recently, there is an increase in demand for the use of biopolymers worldwide, and they are on the verge of replacing conventional petro-based polymers. However, the main drawback that prevents the commercialization of biopolymers is the price when compared to conventional counterparts, which remains the main ultimatum for biopolymers. The $\gamma$ PGA is one of the most expensive biopolymers with diverse applications. Even though there are potent $\gamma$-PGA-producing strains available, the cost of production and recovery remains high. Therefore, the screening of potential $\gamma$-PGA producers using a low-cost medium is an upcoming need to reduce the overall production cost. This issue can be addressed by using a multi-nutritious waste that can replace all the essential nutrients required for $\gamma$-PGA biosynthesis. To achieve this, one should have in-depth knowledge about the various nutritional elements that influence the $\gamma$-PGA production. The future 
research can be focused mainly on exploring various types of fruit and vegetable wastes that could be used directly as the fermentation substrate without supplementation of additional nutrients. These wastes are multi-nutritious, containing organic acids, amino acids, and even high sugar levels, and do not require any pretreatment step. Since they have a short shelf life, a large amount of waste will also be generated, which can be valorized to $\gamma$-PGA resulting in waste valorization and economical production of $\gamma$-PGA. This will ultimately lead to the circular economy, thereby awakening this sleeping giant for its broader commercialization.

Acknowledgements PN and GRN would like to thank CSIR-Senior Research Fellowship. The authors are thankful to Director, CSIRNational Chemical Laboratory, India, for constant support and encouragement.

\section{Declarations}

Conflict of interest The authors declare no competing interests.

\section{References}

1. Kreyenschulte D, Krull R, Margaritis A (2014) Recent advances in microbial biopolymer production and purification. Crit Rev Biotechnol 34:1-15. https://doi.org/10.3109/07388551.2012. 743501

2. Babu RP, O'Connor K, Seeram R (2013) Current progress on biobased polymers and their future trends. Prog Biomater 2:8. https:// doi.org/10.1186/2194-0517-2-8

3. Buescher JM, Margaritis A (2007) Microbial Biosynthesis of Polyglutamic Acid Biopolymer and Applications in the Biopharmaceutical, Biomedical and Food Industries. Crit Rev Biotechnol 27:1-19. https://doi.org/10.1080/ 07388550601166458

4. Sirisansaneeyakul S, Cao M, Kongklom N, Chuensangjun C, Shi $Z$, Chisti Y (2017) Microbial production of poly- $\gamma$-glutamic acid. World J Microbiol Biotechnol 33:173. https://doi.org/10.1007/ s11274-017-2338-y

5. Luo Z, Guo Y, Liu J, Qiu H, Zhao M, Zou W, Li S (2016) Microbial synthesis of poly- $\gamma$-glutamic acid: Current progress, challenges, and future perspectives. Biotechnol Biofuels 9:134

6. Ogunleye A, Bhat A, Irorere VU, Hill D, Williams C, Radecka I (2015) Poly- $\gamma$-glutamic acid: production, properties and applications. Microbiology 161:1-17. https://doi.org/10.1099/mic.0. 081448-0

7. Sung M-H, Park C, Kim C-J, Poo H, Soda K, Ashiuchi M (2005) Natural and edible biopolymer poly- $\gamma$-glutamic acid: synthesis, production, and applications. Chem Rec 5:352-366. https://doi. org/10.1002/tcr.20061

8. Altun M (2019) Bioproduction of $\gamma$-Poly(glutamic acid) using feather hydrolysate as a fermentation substrate. Trak Univ J Nat Sci 20:27-34. https://doi.org/10.23902/trkjnat.448851

9. Kim J, Lee JM, Jang WJ et al (2019) Efficient production of poly $\gamma$-d-glutamic acid from the bloom-forming green macroalgae, Ulva sp., by Bacillus sp. SJ-10. Biotechnol Bioeng 116:15941603

10. Scheel RA, Fusi AD, Min BC, Thomas CM, Ramarao BV, Nomura CT (2019) Increasedproduction of the value-added biopolymers poly(r-3-hydroxyalkanoate) and poly $(\gamma$-glutamic acid) from hydrolyzed paper recycling waste fines. Front Bioeng Biotechnol 7:1-8. https://doi.org/10.3389/fbioe.2019.00409

11. Chen X, Chen S, Sun M, Yu Z (2005) High yield of poly- $\gamma$ glutamic acid from Bacillus subtilis by solid-state fermentation using swine manure as the basis of a solid substrate. Bioresour Technol 96:1872-1879

12. Yong X, Raza W, Yu G, Ran W, Shen Q, Yang X (2011) Optimization of the production of poly- $\gamma$-glutamic acid by Bacillus amyloliquefaciens $\mathrm{C} 1$ in solid-state fermentation using dairy manure compost and monosodium glutamate production residues as basic substrates. Bioresour Technol 102:7548-7554

13. Zeng W, Lin Y, Qi Z, He Y, Wang D, Chen G, Liang Z (2013) An integrated high-throughput strategy for rapid screening of poly $(\gamma-$ glutamic acid)-producing bacteria. Appl Microbiol Biotechnol 97: 2163-2172

14. Chettri R, Bhutia MO, Tamang JP (2016) Poly- $\gamma$-glutamic acid (PGA)-producing Bacillus species isolated from Kinema, Indian fermented soybean food. Front Microbiol 7:971

15. Shih I-L, Van Y-T (2001) The production of poly- $(\gamma$-glutamic acid) from microorganisms and its various applications. Bioresour Technol 79:207-225. https://doi.org/10.1016/S09608524(01)00074-8

16. Wu Q, Xu H, Shi N, Yao J, Li S, Ouyang P (2008) Improvement of poly $(\gamma$-glutamic acid) biosynthesis and redistribution of metabolic flux with the presence of different additives in Bacillus subtilis CGMCC 0833. Appl Microbiol Biotechnol 79:527. https://doi.org/10.1007/s00253-008-1462-x

17. Lee N-R, Go T-H, Lee S-M, Jeong SY, Park GT, Hong CO, Son HJ (2014) In vitro evaluation of new functional properties of poly$\gamma$-glutamic acid produced by Bacillus subtilis D7. Saudi J Biol Sci 21:153-158. https://doi.org/10.1016/j.sjbs.2013.09.004

18. Bajaj IB, Singhal RS (2011) Flocculation properties of poly $(\gamma$ glutamic acid) produced from Bacillus subtilis isolate. Food Bioprocess Technol 4:745-752. https://doi.org/10.1007/s11947009-0186-y

19. Goto A, Kunioka M (1992) Biosynthesis and hydrolysis of poly $(\gamma$-glutamic acid) from Bacillus subtilisIF03335. Biosci Biotechnol Biochem 56:1031-1035

20. Zhang C, Wu D, Ren H (2019) Economical production of agricultural $\gamma$-polyglutamic acid using industrial wastes by Bacillus subtilis. Biochem Eng J 146:117-123

21. Ju W-T, Song Y-S, Jung W-J, Park R-D (2014) Enhanced production of poly- $\gamma$-glutamic acid by a newly-isolated Bacillus subtilis. Biotechnol Lett 36:2319-2324

22. Da Silva SB, Cantarelli VV, Ayub MAZ (2014) Production and optimization of poly- $\gamma$-glutamic acid by Bacillus subtilis BL53 isolated from the Amazonian environment. Bioprocess Biosyst Eng 37:469-479

23. Zhang C, Wu D-J, Jia J, Yang H-Q (2019) Fishmeal wastewater as a low-cost nitrogen source for $\gamma$-polyglutamic acid production using Bacillus subtilis. Waste Biomass Valorization 10:789-795

24. Huang J, Du Y, Xu G et al (2011) High yield and cost-effective production of poly ( $\gamma$-glutamic acid) with Bacillus subtilis. Eng Life Sci 11:291-297

25. Kedia G, Hill D, Hill R, Radecka I (2010) Production of poly- $\gamma$ glutamic acid by Bacillus subtilis and Bacillus licheniformis with different growth media. J Nanosci Nanotechnol 10:5926-5934

26. Ogawa Y, Yamaguchi F, Yuasa K, Tahara Y (1997) Efficient production of $\gamma$-polyglutamic acid by Bacillus subtilis (natto) in jar fermenters. Biosci Biotechnol Biochem 61:1684-1687

27. Zhang D, Feng X, Zhou Z, Zhang Y, Xu H (2012) Economical production of poly ( $\gamma$-glutamic acid) using untreated cane molasses and monosodium glutamate waste liquor by Bacillus subtilis NX-2. Bioresour Technol 114:583-588 
28. Kim S, Dale BE (2004) Global potential bioethanol production from wasted crops and crop residues. Biomass Bioenergy 26: 361-375. https://doi.org/10.1016/j.biombioe.2003.08.002

29. Tang B, Lei P, Xu Z, Jiang Y, Xu Z, Liang J, Feng X, Xu H (2015) Highly efficient rice straw utilization for poly- $(\gamma$-glutamic acid $)$ production by Bacillus subtilis NX-2. Bioresour Technol 193: 370-376. https://doi.org/10.1016/j.biortech.2015.05.110

30. Zhu F, Cai J, Zheng Q, Zhu X, Cen P, Xu Z (2014) A novel approach for poly- $\gamma$-glutamic acid production using xylose and corncob fibres hydrolysate in Bacillus subtilis HB-1. J Chem Technol Biotechnol 89:616-622

31. Wu Q, Xu H, Xu L, Ouyang P (2006) Biosynthesis of poly ( $\gamma$ glutamic acid) in Bacillus subtilis NX-2: regulation of stereochemical composition of poly ( $\gamma$-glutamic acid). Process Biochem 41: 1650-1655

32. Shih IL, Van YT, Chang YN (2002) Application of statistical experimental methods to optimize production of poly $(\gamma-$ glutamic acid) by Bacillus licheniformis CCRC 12826. Enzym Microb Technol 31:213-220

33. Yan S, Yao H, Chen Z, Zeng S, Xi X, Wang Y, He N, Li Q (2015) Poly- $\gamma$-glutamic acid produced from Bacillus licheniformis CGMCC 2876 as a potential substitute for polyacrylamide in the sugarcane industry. Biotechnol Prog 31:1287-1294

34. Lim S-M, Kim J, Shim J-Y, Imm BY, Sung MH, Imm JY (2012) Effect of poly- $\gamma$-glutamic acids (PGA) on oil uptake and sensory quality in doughnuts. Food Sci Biotechnol 21:247-252. https:// doi.org/10.1007/s10068-012-0032-2

35. Du G, Yang G, Qu Y et al (2005) Effects of glycerol on the production of poly ( $\gamma$-glutamic acid) by Bacillus licheniformis. Process Biochem 40:2143-2147

36. Wei X, Ji Z, Chen S (2010) Isolation of halotolerant Bacillus licheniformis WX-02 and regulatory effects of sodium chloride on yield and molecular sizes of poly- $\gamma$-glutamic acid. Appl Biochem Biotechnol 160:1332-1340

37. Cromwick A-M, Gross RA (1995) Effects of manganese (II) on Bacillus licheniformis ATCC 9945A physiology and $\gamma$-poly (glutamic acid) formation. Int J Biol Macromol 17:259-267

38. Chatterjee PM, Datta S, Tiwari DP, Raval R, Dubey AK (2018) Selection of an effective indicator for rapid detection of microorganisms producing $\gamma$-polyglutamic acid and its biosynthesis under submerged fermentation conditions using Bacillus methylotrophicus. Appl Biochem Biotechnol 185:270-288

39. Ito Y, Tanaka T, Ohmachi T, Asada Y (1996) Glutamic acid independent production of poly ( $\gamma$-glutamic acid) by Bacillus subtilis TAM-4. Biosci Biotechnol Biochem 60:1239-1242

40. Zhang H, Zhu J, Zhu X, Cai J, Zhang A, Hong Y, Huang J, Huang L, Xu Z (2012) High-level exogenous glutamic acid-independent production of poly-( $\gamma$-glutamic acid) with organic acid addition in a new isolated Bacillus subtilis C10. Bioresour Technol 116:241246

41. Zeng W, Chen G, Guo Y, Zhang B, Dong M, Wu Y, Wang J, Che $Z$, Liang Z (2017) Production of poly- $\gamma$-glutamic acid by a thermotolerant glutamate-independent strain and comparative analysis of the glutamate dependent difference. AMB Express 7: 213

42. Soliman NA, Berekaa MM, Abdel-Fattah YR (2005) Polyglutamic acid (PGA) production by Bacillus sp. SAB-26: application of Plackett-Burman experimental design to evaluate culture requirements. Appl Microbiol Biotechnol 69:259-267

43. Mabrouk M, Abou-Zeid D, Sabra W (2012) Application of Plackett-Burman experimental design to evaluate nutritional requirements for poly ( $\gamma$-glutamic acid) production in batch fermentation by Bacillus licheniformis A13. Afr J Appl Microbiol Res 1: 6-18

44. Kongklom N, Shi Z, Chisti Y, Sirisansaneeyakul S (2017) Enhanced production of poly- $\gamma$-glutamic acid by Bacillus licheniformis TISTR 1010 with environmental controls. Appl Biochem Biotechnol 182:990-999

45. Kongklom N, Luo H, Shi Z, Pechyen C, Chisti Y, Sirisansaneeyakul S (2015) Production of poly- $\gamma$-glutamic acid by glutamic acid-independent Bacillus licheniformis TISTR 1010 using different feeding strategies. Biochem Eng J 100:67-75

46. Gao W, He Y, Zhang F, Zhao F, Huang C, Zhang Y, Zhao Q, Wang S, Yang C (2019) Metabolic engineering of Bacillus amyloliquefaciens LL 3 for enhanced poly- $\gamma$-glutamic acid synthesis. Microb Biotechnol 12:932-945. https://doi.org/10.1111/ 1751-7915.13446

47. Wang Q, Wei X, Chen S (2017) Production and application of poly- $\gamma$-glutamic acid. In: Current developments in biotechnology and bioengineering. Elsevier, pp 693-717

48. Ashiuchi M (2010) Occurrence and biosynthetic mechanism of poly-gamma-glutamic acid. In: amino-acid homopolymers occurring in nature. Springer, Berlin, Heidelberg, pp 77-93

49. Ashiuchi M, Kamei T, Baek D-H, Shin SY, Sung MH, Soda K, Yagi T, Misono H (2001) Isolation of Bacillus subtilis (chungkookjang), a poly- $\gamma$-glutamate producer with high genetic competence. Appl Microbiol Biotechnol 57:764-769. https://doi. org/10.1007/s00253-001-0848-9

50. Jiang F, Qi G, Ji Z, Zhang S, Liu J, Ma X, Chen S (2011) Expression of glr gene encoding glutamate racemase in Bacillus licheniformis WX-02 and its regulatory effects on synthesis of poly- $\gamma$-glutamic acid. Biotechnol Lett 33:1837-1840. https://doi. org/10.1007/s10529-011-0631-7

51. Candela T, Fouet A (2006) Poly-gamma-glutamate in bacteria. Mol Microbiol 60:1091-1098. https://doi.org/10.1111/j.13652958.2006.05179.x

52. Urushibata Y, Tokuyama S, Tahara Y (2002) Characterization of the Bacillus subtilis ywsC gene, involved in $\gamma$-polyglutamic acid production. J Bacteriol 184:337-343. https://doi.org/10.1128/JB. 184.2.337-343.2002

53. Cao M, Feng J, Sirisansaneeyakul S, Song C, Chisti Y (2018) Genetic and metabolic engineering for microbial production of poly- $\gamma$-glutamic acid. Biotechnol Adv 36:1424-1433. https:// doi.org/10.1016/j.biotechadv.2018.05.006

54. Ashiuchi M, Shimanouchi K, Horiuchi T et al (2006) Genetically engineered poly- $\gamma$-glutamate producer from Bacillus subtilis ISW1214. Biosci Biotechnol Biochem 70:1794-1797. https:// doi.org/10.1271/bbb.60082

55. Yeh CM, Wang JP, Lo SC, Chan WC, Lin MY (2010) Chromosomal integration of a synthetic expression control sequence achieves poly- $\gamma$-glutamate production in a Bacillus subtilis strain. Biotechnol Prog 26:1001-1007. https://doi.org/ 10.1002/btpr.417

56. Kimura K (2004) Characterization of Bacillus subtilis glutamyltransferase and its involvement in the degradation of capsule poly- -glutamate. Microbiology 150:4115-4123. https:// doi.org/10.1099/mic.0.27467-0

57. Kimura K, Fujimoto Z (2010) Enzymatic degradation of polygamma-glutamic acid. In: Amino-acid homopolymers occurring in nature. Springer, Berlin, Heidelberg, pp 95-117

58. Scoffone V, Dondi D, Biino G, Borghese G, Pasini D, Galizzi A, Calvio C (2013) Knockout of pgdS and ggt genes improves $\gamma$ PGA yield in B. subtilis. Biotechnol Bioeng 110:2006-2012. https://doi.org/10.1002/bit.24846

59. Ohsawa T, Tsukahara K, Ogura M (2009) Bacillus subtilis response regulator degu is a direct activator of pgsb transcription involved in $\gamma$-poly-glutamic acid synthesis. Biosci Biotechnol Biochem 73:2096-2102. https://doi.org/10.1271/bbb.90341

60. Feng J, Gu Y, Quan Y, Cao M, Gao W, Zhang W, Wang S, Yang C, Song C (2015) Improved poly- $\gamma$-glutamic acid production in Bacillus amyloliquefaciensby modular pathway engineering. 
Metab Eng 32:106-115. https://doi.org/10.1016/j.ymben.2015. 09.011

61. Zhang W, He Y, Gao W, Feng J, Cao M, Yang C, Song C, Wang $S$ (2015) Deletion of genes involved in glutamate metabolism to improve poly-gamma-glutamic acid production in B. amyloliquefaciens LL3. J Ind Microbiol Biotechnol 42:297305. https://doi.org/10.1007/s10295-014-1563-8

62. Cai D, He P, Lu X, Zhu C, Zhu J, Zhan Y, Wang Q, Wen Z, Chen $S$ (2017) A novel approach to improve poly- $\gamma$-glutamic acid production by NADPH regeneration in Bacillus licheniformis WX02. Sci Rep 7. https://doi.org/10.1038/srep43404

63. Zhang W, Xie H, He Y, Feng J, Gao W, Gu Y, Wang S, Song C (2013) Chromosome integration of the Vitreoscilla hemoglobin gene (vgb) mediated by temperature-sensitive plasmid enhances $\gamma$-PGA production in Bacillus amyloliquefaciens. FEMS Microbiol Lett 343:127-134. https://doi.org/10.1111/1574-6968. 12139

64. Gao W, Zhang Z, Feng J, Dang Y, Quan Y, Gu Y, Wang S, Song C (2016) Effects of MreB paralogs on poly- $\gamma$-glutamic acid synthesis and cell morphology inBacillus amyloliquefaciens. FEMS Microbiol Lett 363. https://doi.org/10.1093/femsle/fnw187

65. Cao M, Geng W, Zhang W, Sun J, Wang S, Feng J, Zheng P, Jiang A, Song C (2013) Engineering of recombinant Escherichia colicells co-expressing poly- $\gamma$ - glutamic acid ( $\gamma$-PGA) synthetase and glutamate racemase for differential yielding of $\gamma$-PGA. Microb Biotechnol 6:675-684. https://doi.org/10.1111/17517915.12075

66. Hirasawa T, Shimizu H (2016) Recent advances in amino acid production by microbial cells. Curr Opin Biotechnol 42:133146. https://doi.org/10.1016/j.copbio.2016.04.017

67. Scheel RA, Fusi AD, Min BC, Thomas CM, Ramarao BV, Nomura CT (2019) Increased production of the value-added biopolymers poly (r-3-hydroxyalkanoate) and poly ( $\gamma$-glutamic acid) from hydrolyzed paper recycling waste fines. Front Bioeng Biotechnol 7:409. https://doi.org/10.3389/fbioe.2019.00409

68. Manocha B, Margaritis A (2010) A novel method for the selective recovery and purification of $\gamma$-polyglutamic acid from Bacillus licheniformisfermentation broth. Biotechnol Prog 26:734-742

69. Hashino M, Katagiri T, Kubota N, Ohmukai Y, Maruyama T, Matsuyama H (2011) Effect of surface roughness of hollow fiber membranes with gear-shaped structure on membrane fouling by sodium alginate. J Membr Sci 366:389-397

70. Gunawan P, Guan C, Song X, Zhang Q, Leong SSJ, Tang C, Chen Y, Chan-Park MB, Chang MW, Wang K, Xu R (2011) Hollow fiber membrane decorated with Ag/MWNTs: Toward effective water disinfection and biofouling control. ACS Nano 5:1003310040. https://doi.org/10.1021/nn2038725

71. Do JH, Chang HN, Lee SY (2001) Efficient recovery of $\gamma$-poly (glutamic acid) from highly viscous culture broth. Biotechnol Bioeng 76:219-223

72. Akagi T, Matsusaki M, Akashi M (2010) Pharmaceutical and medical applications of poly-gamma-glutamic acid. In: Aminoacid homopolymers occurring in nature. Springer, Berlin, Heidelberg, pp 119-153

73. Mohapatra S, Maity S, Dash HR, Das S, Pattnaik S, Rath CC, Samantaray D (2017) Bacillus and biopolymer: prospects and challenges. Biochem Biophys Rep 12:206-213. https://doi.org/ 10.1016/j.bbrep.2017.10.001

74. Bayer EA, Lamed R, Himmel ME (2007) The potential of cellulases and cellulosomes for cellulosic waste management. Curr Opin Biotechnol 18:237-245. https://doi.org/10.1016/j.copbio. 2007.04.004

75. Liu C, Wei M, Wang J, Xu J, Jiang J, Wang K (2020) Facile directional conversion of cellulose and bamboo meal wastes over low-cost sulfate and polar aprotic solvent. ACS Sustain Chem Eng 8(14):5776-5786
76. Xu Z, Shi F, Cen P (2005) Production of polyglutamic acid from mixed glucose and sucrose by Co-cultivation of Bacillus subtilis and Corynebacterium glutamicum. In: The $2005 \mathrm{AIChE}$ annual meeting, Cincinnati

77. Jose AA, G. A, Pandey A, Binod P (2018) Production optimization of poly- $\gamma$-glutamic acid by Bacillus amyloliquefaciensunder solid-state fermentation using soy hull as substrate. Indian $\mathrm{J}$ Biotechnol 17:44-49

78. Feng J, Gu Y, Sun Y, Han L, Yang C, Zhang W, Cao M, Song C, Gao W, Wang S (2014) Metabolic engineering of Bacillus amyloliquefaciens for poly-gamma-glutamic acid ( $\gamma$-PGA) overproduction. Microb Biotechnol 7:446-455. https://doi.org/10. 1111/1751-7915.12136

79. Singh V, Haque S, Niwas R, Srivastava A, Pasupuleti M, Tripathi CKM (2017) Strategies for fermentation medium optimization: an in-depth review. Front Microbiol 7:2087. https://doi.org/10.3389/ fmicb.2016.02087

80. Zeng W, Chen G, Wu Y, Dong M, Zhang B, Liang Z (2018) Nonsterilized fermentative production of poly- $\gamma$-glutamic acid from cassava starch and corn steep powder by a thermophilic Bacillus subtilis. J Chem Technol Biotechnol 93:2917-2924. https://doi.org/10.1002/jctb.5646

81. Shi S, Liang Y, Zhang MM, Ang EL, Zhao H (2016) A highly efficient single-step, markerless strategy for multi-copy chromosomal integration of large biochemical pathways in Saccharomyces cerevisiae. Metab Eng 33:19-27. https://doi.org/ 10.1016/j.ymben.2015.10.011

82. Liu Z, Liang Y, Ang EL, Zhao H (2017) A new era of genome integration - simply cut and paste! ACS Synth Biol 6:601-609. https://doi.org/10.1021/acssynbio.6b00331

83. Zhou YJ, Gao W, Rong Q, Jin G, Chu H, Liu W, Yang W, Zhu Z, Li G, Zhu G, Huang L, Zhao ZK (2012) Modular pathway engineering of diterpenoid synthases and the mevalonic acid pathway for miltiradiene production. J Am Chem Soc 134:3234-3241. https://doi.org/10.1021/ja2114486

84. Zou R, Zhou K, Stephanopoulos G, Too HP (2013) Combinatorial engineering of 1-deoxy-d-xylulose 5- phosphate pathway using cross-lapping in vitro assembly ( CLIVA ) Method. PLoS One 8:1-12. https://doi.org/10.1371/journal.pone.0079557

85. Tian T, Kang JW, Kang A, Lee TS (2019) Redirecting metabolic flux via combinatorial multiplex crispri-mediated repression for isopentenol production in Escherichia coli. ACS Synth Biol 8: 391-402. https://doi.org/10.1021/acssynbio.8b00429

86. Navale GR, Dharne MS, Shinde SS (2020) Metabolic engineering and synthetic biology for isoprenoid production in Escherichia coli and Saccharomyces cerevisiae. Appl Microbiol Biotechnol 105:457-475. https://doi.org/10.1007/s00253-02011040-w

87. Jakočiunas T, Jensen MK, Keasling JD (2016) CRISPR/Cas9 advances engineering of microbial cell factories. Metab Eng 34:44 59

88. Cheng C, Asada Y, Aida T (1989) Production of $\gamma$-polyglutamic acid by Bacillus licheniformis A35 under denitrifying conditions. Agric Biol Chem 53:2369-2375

89. Ko YH, Gross RA (1998) Effects of glucose and glycerol on $\gamma$ poly (glutamic acid) formation by Bacilluslicheniformis ATCC 9945a. Biotechnol Bioeng 57:430-437

90. Yoon SH, Do JH, Lee SY, Chang HN (2000) Production of poly$\gamma$-glutamic acid by fed-batch culture of Bacillus licheniformis. Biotechnol Lett 22:585-588

91. Qiao C, Zhang S, Li Z, Chen X, Li X, Lan L (2013) Improving poly-( $\gamma$-glutamic acid) production and reducing impurities in fermentation broth by medium optimization using Bacillus. licheniformis CGMCC3336. J Biobased Mater Bioenergy 7: 390-394 
92. Zhao C, Zhang Y, Wei X, Hu Z, Zhu F, Xu L, Luo M, Liu H (2013) Production of ultra-high molecular weight poly- $\gamma$-glutamic acid with Bacillus licheniformis P-104 and characterization of its flocculation properties. Appl Biochem Biotechnol 170:562-572

93. Kumar R, Pal P (2015) Fermentative production of poly $(\gamma$ glutamic acid) from renewable carbon source and downstream purification through a continuous membrane-integrated hybrid process. Bioresour Technol 177:141-148

94. Mahaboob Ali AA, Momin B, Ghogare P (2020) Isolation of a novel poly- $\gamma$-glutamic acid-producing Bacillus licheniformis A14 strain and optimization of fermentation conditions for high-level production. Prep Biochem Biotechnol 50:445-452. https://doi. org/10.1080/10826068.2019.1706560

95. Azarhava H, Bajestani MI, Jafari A, Vakilchap F, Mousavi SM (2020) Production and physicochemical characterization of bacterial poly gamma-(glutamic acid) to investigate its performance on enhanced oil recovery. Int J Biol Macromol 147:1204-1212

96. Kubota H, Matsunobu T, Uotani K, Takebe H, Satoh A, Tanaka T, Taniguchi M (1993) Production of poly ( $\gamma$-glutamic acid) by Bacillus subtilis F-2-01. Biosci Biotechnol Biochem 57:12121213

97. Richard A, Margaritis A (2003) Optimization of cell growth and poly (glutamic acid) production in batch fermentation by Bacillus subtilis. Biotechnol Lett 25:465-468

98. Shih L, Wu P-J, Shieh C-J (2005) Microbial production of a poly ( $\gamma$-glutamic acid) derivative by Bacillus subtilis. Process Biochem 40:2827-2832

99. Xu H, Jiang M, Li H, Lu D, Ouyang P (2005) Efficient production of poly ( $\gamma$-glutamic acid) by newly isolated Bacillus subtilis NX2. Process Biochem 40:519-523

100. Shi F, Xu Z, Cen P (2006) Optimization of $\gamma$-polyglutamic acid production byBacillus subtilis ZJU-7 using a surface-response methodology. Biotechnol Bioprocess Eng 11:251-257

101. Chen J, Shi F, Zhang B, Zhu F, Cao W, Xu Z, Xu G, Cen P (2010) Effects of cultivation conditions on the production of $\gamma$-PGA with Bacillus subtilis ZJU-7. Appl Biochem Biotechnol 160:370-377

102. Yao J, Xu H, Shi N, Cao X, Feng X, Li S, Ouyang P (2010) Analysis of carbon metabolism and improvement of $\gamma$ polyglutamic acid production from Bacillus subtilisNX-2. Appl Biochem Biotechnol 160:2332-2341

103. Wu Q, Xu H, Liang J, Yao J (2010) Contribution of glycerol on production of poly ( $\gamma$-glutamic acid) in Bacillus subtilis NX-2. Appl Biochem Biotechnol 160:386-392

104. Zhang D, Xu Z, Xu H, Feng X, Li S, Cai H, Wei Y, Ouyang P (2011) Improvement of poly ( $\gamma$-glutamic acid) biosynthesis and quantitative metabolic flux analysis of a two-stage strategy for agitation speed control in the culture of Bacillus subtilis NX-2. Biotechnol Bioprocess Eng 16:1144-1151

105. Bhunia B, Mukhopadhy D, Goswami S, Mandal T, Dey A (2012) Improved production, characterization and flocculation properties of poly $(\gamma)$-glutamic acid produced from Bacillus subtilis. J Biochem Technol 3(4)

106. Lee N-R, Lee S-M, Cho K-S, Jeong SY, Hwang DY, Kim DS, Hong CO, Son HJ (2014) Improved production of poly- $\gamma$ glutamic acid by Bacillus subtilis D7 isolated from Doenjang, a korean traditional fermented food, and its antioxidant activity. Appl Biochem Biotechnol 173:918-932

107. Xu Z, Feng X, Zhang D, Tang B, Lei P, Liang J, Xu H (2014) Enhanced poly ( $\gamma$-glutamic acid) fermentation by Bacillus subtilisNX-2 immobilized in an aerobic plant fibrous-bed bioreactor. Bioresour Technol 155:8-14

108. Peng Y, Jiang B, Zhang T, Mu W, Miao M, Hua Y (2015) Highlevel production of poly ( $\gamma$-glutamic acid) by a newly isolated glutamate-independent strain, Bacillus methylotrophicus. Process Biochem 50:329-335
109. Moraes LP, Alegre RM, Brito PN (2012) Optimisation of poly ( $\gamma$ glutamic acid) production by Bacillus velezensis NRRL B-23189 in liquid fermentation with molasses as the carbon source without addition of glutamic acid. Rev Chem Eng 4:618-623

110. Jung D-Y, Jung S, Yun J-S, Kim JN, Wee YJ, Jang HG, Ryu HW (2005) Influences of cultural medium component on the production of poly ( $\gamma$-glutamic acid) byBacillus sp. RKY3. Biotechnol Bioprocess Eng 10:289-295

111. Jeong J-H, Kim J-N, Wee Y-J, Ryu H-W (2010) The statistically optimized production of poly ( $\gamma$-glutamic acid) by batch fermentation of a newly isolated Bacillus subtilis RKY3. Bioresour Technol 101:4533-4539

112. Wang D, Hwang J-S, Kim D-H, Lee S, Kim DH, Joe MH (2020) A newly isolated Bacillus siamensis SB1001 for mass production of poly- $\gamma$-glutamic acid. Process Biochem 92:164-173

113. Ahmed RF (2020) Optimization of some nutritional conditions and $\alpha$-ketoglutaric acid concentration as pga precursor for maximizing PGA production from Bacillus sp. 42 and Bacillus sonorensis. Microbiol Res J Int 44:34-42

114. Fang J, Liu Y, Huan C, Xu L, Ji G, Yan Z (2020) Comparison of poly- $\gamma$-glutamic acid production between sterilized and nonsterilized solid-state fermentation using agricultural waste as substrates. J Clean Prod 255:120248

115. Wang D, Kim H, Lee S et al (2020) High-level production of poly$\gamma$-glutamic acid from untreated molasses by Bacillus siamensis IR10. Microb Cell Factories 19:1-13

116. Liang J, Shi W, He Z, Pang L, Zhang Y (2019) Effects of poly- $\gamma$ glutamic acid on water use efficiency, cotton yield, and fiber quality in the sandy soil of southern Xinjiang, China. Agric Water Manag 218:48-59

117. Guo J, Shi W, Wen L, Shi X, Li J (2020) Effects of a superabsorbent polymer derived from poly- $\gamma$-glutamic acid on water infiltration, field water capacity, soil evaporation, and soil waterstable aggregates. Arch Agron Soil Sci 66:1627-1638

118. Bai N, Zhang H, Li S, Zheng X, Zhang J, Sun L, Lv W (2020) Effects of application rates of poly- $\gamma$-glutamic acid on vegetable growth and soil bacterial community structure. Appl Soil Ecol 147:103405

119. Chang J, Zhong Z, Hong XU et al (2013) Fabrication of poly ( $\gamma$ glutamic acid)-coated $\mathrm{Fe}_{3} \mathrm{O}_{4}$ magnetic nanoparticles and their application in heavy metal removal. Chin J Chem Eng 21:12441250

120. Inbaraj BS, Wang JS, Lu JF, Siao FY, Chen BH (2009) Adsorption of toxic mercury (II) by an extracellular biopolymer poly ( $\gamma$-glutamic acid). Bioresour Technol 100:200-207

121. Hajdu I, Bodnár M, Csikós Z et al (2012) Combined nanomembrane technology for removal of lead ions. J Membr Sci 409:44-53

122. Peng YP, Chang YC, Chen KF, Wang CH (2020) A field pilotscale study on heavy metal-contaminated soil washing by using an environmentally friendly agent - poly- $\gamma$-glutamic acid $(\gamma$-PGA). Environ Sci Pollut Res 27:34760-34769. https://doi.org/10.1007/ s11356-019-07444-5

123. Sakamoto S, Kawase Y (2016) Adsorption capacities of poly- $\gamma$ glutamic acid and its sodium salt for cesium removal from radioactive wastewaters. J Environ Radioact 165:151-158

124. Fang Y, Zhu X, Wang N, Zhang X, Yang D, Nie J, Ma G (2019) Biodegradable core-shell electrospun nanofibers based on PLA and $\gamma$-PGA for wound healing. Eur Polym J 116:30-37

125. Wang Y, Dou C, He G, Ban L, Huang L, Li Z, Gong J, Zhang J, Yu P (2018) Biomedical potential of ultrafine ag nanoparticles coated on poly (Gamma-Glutamic Acid) hydrogel with special reference to wound healing. Nanomaterials 8:324

126. Liu W-C, Wang H-Y, Lee T-H, Chung R-J (2019) Gamma-poly glutamate/gelatin composite hydrogels crosslinked by 
proanthocyanidins for wound healing. Mater Sci Eng C 101:630 639

127. Tsao CT, Chang CH, Lin YY, Wu MF, Wang JL, Young TH, Han JL, Hsieh KH (2011) Evaluation of chitosan/ $\gamma$-poly (glutamic acid) polyelectrolyte complex for wound dressing materials. Carbohydr Polym 84:812-819

128. Bae SR, Park C, Choi JC et al (2010) Effects of ultra high molecular weight poly- $\gamma$-glutamic acid from Bacillus subtilis(chungkookjang) on corneal wound healing. J Microbiol Biotechnol. https://doi.org/10.4014/jmb.0911.11021

129. Qamar Z, Rahim ZBHA, Neon GS et al (2019) Effectiveness of poly- $\gamma$-glutamic acid in maintaining enamel integrity. Arch Oral Biol 106:104482

130. Yao C-H, Yang S-P, Chen Y-S, Chen K-Y (2019) Electrospun poly $(\gamma$-glutamic acid $) / \beta$-tricalcium phosphate composite fibrous mats for bone regeneration. Polymers (Basel) 11:227

131. Fang J, Zhang Y, Yan S, Liu Z, He S, Cui L, Yin J (2014) Poly (Lglutamic acid)/chitosan polyelectrolyte complex porous microspheres as cell microcarriers for cartilage regeneration. Acta Biomater 10:276-288

132. Park S-B, Sung M-H, Uyama H, Han DK (2021) Poly(glutamic acid): Production, composites, and medical applications of the next-generation biopolymer. Prog Polym Sci 113:101341. https://doi.org/10.1016/j.progpolymsci.2020.101341

133. Yang R, Wang X, Liu S, Zhang W, Wang P, Liu X, Ren Y, Tan X, Chi B (2020) Bioinspired poly ( $\gamma$-glutamic acid) hydrogels for enhanced chondrogenesis of bone marrow-derived mesenchymal stem cells. Int J Biol Macromol 142:332-344

134. Zhang L, Chang J, Zhao Y, Xu H, Wang T, Li Q, Xing L, Huang J, Wang Y, Liang Q (2018) Fabrication of a triptolide-loaded and poly- $\gamma$-glutamic acid-based amphiphilic nanoparticle for the treatment of rheumatoid arthritis. Int J Nanomedicine 13:2051-2064

135. Lee B, Jo S, Kim S-M, Cho ML, Park SH, Youn J, Ji JD, Kim TH (2018) Poly- $\gamma$-glutamic acid suppresses osteoclastogenesis in human osteoclast precursors and prevents joint damage in a collageninduced murine arthritis model. Immunol Lett 203:80-86

136. Xiong Y, Jiang W, Shen Y, Li H, Sun C, Ouahab A, Tu J (2012) A poly $(\gamma, \mathrm{L}$-glutamic acid)-citric acid based nanoconjugate for cisplatin delivery. Biomaterials 33:7182-7193

137. Ye H, Jin L, Hu R, Yi Z, Li J, Wu Y, Xi X, Wu Z (2006) Poly ( $\gamma, 1$ glutamic acid)-cisplatin conjugate effectively inhibits human breast tumor xenografted in nude mice. Biomaterials 27:59585965

138. Keresztessy Z, Bodnár M, Ber E, Hajdu I, Zhang M, Hartmann JF, Minko T, Borbély J (2009) Self-assembling chitosan/poly- $\gamma$ glutamic acid nanoparticles for targeted drug delivery. Colloid Polym Sci 287:759-765

139. Bai Y, Zhang Z, Zhang A, Chen L, He C, Zhuang X, Chen X (2012) Novel thermo-and pH-responsive hydroxypropyl cellulose-and poly (l-glutamic acid)-based microgels for oral insulin controlled release. Carbohydr Polym 89:1207-1214

140. Cho S-H, Kim A, Shin W, Heo MB, Noh HJ, Hong KS, Cho JH, Lim YT (2017) Photothermal-modulated drug delivery and magnetic relaxation based on collagen/poly ( $\gamma$-glutamic acid) hydrogel. Int J Nanomedicine 12:2607-2620
141. Sakuma S, Sagawa T, Masaoka Y, Kataoka M, Yamashita S, Shirasaka Y, Tamai I, Ikumi Y, Kida T, Akashi M (2009) Stabilization of enzyme-susceptible glucoside bonds of phloridzin through conjugation with poly ( $\gamma$-glutamic acid). J Control Release 133:125-131

142. Hsu S, Lin C-H (2007) The properties of gelatin-poly ( $\gamma$-glutamic acid) hydrogels as biological glues. Biorheology 44:17-28

143. Karimi M, Yazdi FT, Mortazavi SA, Shahabi-Ghahfarrokhi I, Chamani J (2020) Development of active antimicrobial poly (1glutamic) acid-poly (1-lysine) packaging material to protect probiotic bacterium. Polym Test 83:106338

144. Sabbah M, Di Pierro P, Ruffo F et al (2020) Glutamic Acid as Repeating Building Block for Bio-Based Films. Polymers (Basel): 12. https://doi.org/10.3390/polym 12071613

145. Ashiuchi M, Fukushima K, Oya H, Hiraoki T, Shibatani S, Oka N, Nishimura H, Hakuba H, Nakamori M, Kitagawa M (2013) Development of Antimicrobial Thermoplastic Material from Archaeal Poly- $\gamma$-L-Glutamate and Its Nanofabrication. ACS Appl Mater Interfaces 5:1619-1624. https://doi.org/10.1021/ am3032025

146. Pisani S, Dorati R, Scocozza F, Mariotti C, Chiesa E, Bruni G, Genta I, Auricchio F, Conti M, Conti B (2020) Preliminary investigation on a new natural based poly(- $\gamma$-glutamic acid)/Chitosan bioink. J Biomed Mater Res Part B Appl Biomater 108:27182732. https://doi.org/10.1002/jbm.b.34602

147. Wang R, Wang X, Zhan Y, Xu Z, Xu Z, Feng X, Li S, Xu H (2019) A Dual Network Hydrogel Sunscreen Based on Poly- $\gamma$ glutamic Acid/Tannic Acid Demonstrates Excellent Anti-UV, Self-Recovery, and Skin-Integration Capacities. ACS Appl Mater Interfaces 11:37502-37512

148. Su C-Y, Chen C-C, Chen H-Y, Lin CP, Lin FH, Fang HW (2019) Characteristics of an alternative antibacterial biomaterial for mouthwash in the absence of alcohol. J Dent Sci 14:192-197

149. Choi J-C, Uyama H, Lee C-H, Sung M-H (2015) In vivo hair growth promotion effects of ultra-high molecular weight poly- $\gamma$ glutamic acid from Bacillus subtilis (Chungkookjang). J Microbiol Biotechnol 25:407-412

150. Kim HS, Kwon H-K, Lee DH, le TN, Park HJ, Kim MI (2019) Poly ( $\gamma$-Glutamic Acid)/Chitosan Hydrogel Nanoparticles For Effective Preservation And Delivery Of Fermented Herbal Extract For Enlarging Hair Bulb And Enhancing Hair Growth. Int J Nanomedicine 14:8409-8419

151. Su C-Y, Yeh L-K, Lai C-C, Dubuisson M, Tsao YF, Tseng CL, Fang HW (2020) The bio-tribological effect of poly-Gammaglutamic acid in the lysozyme-ionic contact lens system. Polymers (Basel) 12:156

152. Sakai K, Sonoda C, Murase K (2000) Bitterness relieving agent. JP patent WO0021390

153. Mitsuiki M, Mizuno A, Tanimoto H, Motoki M (1998) Relationship between the Antifreeze Activities and the Chemical Structures of Oligo- and Poly(glutamic acid)s. J Agric Food Chem 46:891-895. https://doi.org/10.1021/jf970797m

Publisher's Note Springer Nature remains neutral with regard to jurisdictional claims in published maps and institutional affiliations. 